\title{
CDK4/6 Inhibitor Treatments in Patients with Hormone Receptor Positive, Her2 Negative Advanced Breast Cancer: Potential Molecular Mechanisms, Clinical Implications and Future Perspectives
}

\author{
Michela Roberto ${ }^{1, *(\mathbb{D}}$, Antonio Astone ${ }^{2}$, Andrea Botticelli ${ }^{3}$, Luisa Carbognin ${ }^{4}$, Alessandra Cassano ${ }^{5}$, \\ Giuliana D'Auria ${ }^{6}$, Agnese Fabbri ${ }^{7}$, Alessandra Fabi ${ }^{8}$, Teresa Gamucci ${ }^{6}$, Eriseld Krasniqi ${ }^{9}$, Mauro Minelli ${ }^{10}$, \\ Armando Orlandi $\left.{ }^{5}{ }^{(}\right)$, Francesco Pantano ${ }^{11}$, Ida Paris ${ }^{4}{ }^{(}$, Laura Pizzuti ${ }^{9}$, Ilaria Portarena ${ }^{12}$, Nello Salesi ${ }^{13}$, \\ Simone Scagnoli ${ }^{14}\left[\right.$, Paola Scavina ${ }^{10}$, Giuseppe Tonini ${ }^{11}$, Patrizia Vici ${ }^{9}$ and Paolo Marchetti ${ }^{1,3}$ (I)
}

1 Oncology Unit, Department of Clinical and Molecular Medicine, Sant'Andrea Hospital, Sapienza University of Rome, Via di Grottarossa 1035-1039, 00189 Rome, Italy; paolo.marchetti@uniroma1.it

2 Division of Medical Oncology, Fatebenefratelli San Pietro Hospital, 00189 Rome, Italy; astone.antonio@fbfrm.it

3 Medical Oncology Unit B, Policlinico Umberto I, 00161 Rome, Italy; Andrea.botticelli@uniroma1.it

4 Department of Woman and Child Health and Public Health, Fondazione Policlinico Universitario A. Gemelli IRCCS, 00168 Rome, Italy; luisa.carbognin@guest.policlinicogemelli.it (L.C.); ida.paris@policlinicogemelli.it (I.P.)

check for updates

Citation: Roberto, M.; Astone, A.; Botticelli, A.; Carbognin, L.; Cassano, A.; D'Auria, G.; Fabbri, A.; Fabi, A.; Gamucci, T.; Krasniqi, E.; et al. CDK4/ 6 Inhibitor Treatments in Patients with Hormone Receptor Positive, Her2 Negative Advanced Breast Cancer: Potential Molecular Mechanisms, Clinical Implications and Future Perspectives. Cancers 2021, 13, 332. https://doi.org/10.3390/ cancers13020332

Received: 14 December 2020

Accepted: 12 January 2021

Published: 18 January 2021

Publisher's Note: MDPI stays neutral with regard to jurisdictional claims in published maps and institutional affiliations.

Copyright: (c) 2021 by the authors. Licensee MDPI, Basel, Switzerland. This article is an open access article distributed under the terms and conditions of the Creative Commons Attribution (CC BY) license (https:// creativecommons.org/licenses/by/ $4.0 /)$.
5 Department of Medical Oncology, Catholic University of Sacred Heart, 00168 Rome, Italy; Alessandra.cassano@policlinicogemelli.it (A.C.); armando.orlandi@policlinicogemelli.it (A.O.)

6 Medical Oncology, Sandro Pertini Hospital, 00157 Rome, Italy; Giuliana.dauria@aslroma2.it (G.D.); teresa.gamucci@aslroma2.it (T.G.)

7 Medical Oncology Unit, Belcolle Hospital, 01100 Viterbo, Italy; mariaagnese.fabbri@asl.vt.it

8 Phase 1 Unit and Pre+cision Medicine, IRCCS Regina Elena National Cancer Institute, 00144 Rome, Italy; alessandra.fabi@policlinicogemelli.it

9 Division of Medical Oncology 2, IRCCS Regina Elena National Cancer Institute, 00144 Rome, Italy; eriseld.krasniqi@ifo.gov.it (E.K.); laura.pizzuti@ifo.gov.it (L.P.); patrizia.vici@ifo.gov.it (P.V.)

10 San Giovanni Addolorata Hospital, 00184 Rome, Italy; mminelli@hsangiovanni.roma.it (M.M.); paola.scavina@hsangiovanni.roma.it (P.S.)

11 Department of Oncology, University Campus Biomedico of Rome, 00155 Rome, Italy; F.pantano@unicampus.it (F.P.); g.tonini@unicampus.it (G.T.)

12 Medical Oncology Unit, Department of Systems Medicine, Tor Vergata Clinical Center University Hospital, 00133 Rome, Italy; ilaria.portarena@ptvonline.it

13 Medical Oncology, S.M. Goretti Hospital, 04100 Latina, Italy; n.salesi@ausl.latina.it

14 Department of Medical and Surgical Sciences and Translational Medicine, Sapienza University of Rome, 00185 Rome, Italy; simone.scagnoli@uniroma1.it

* Correspondence: michela.roberto@uniroma1.it

Simple Summary: The recent addition of cyclin-dependent kinase 4 (CDK4) and CDK6 inhibitors (palbociclib, ribociclib, abemaciclib) to endocrine therapy have remarkably improved the outcome of patients with HR+ advanced breast cancer. However, some points of reflections are still undiscussed. To answer these questions, we revised the mechanism of action of CDK4-6 inhibitors, clinical data available from pivotal studies, and summarized potential future strategies to overcome resistance to CDK4-6 inhibitors, thus improving patient's survival.

Abstract: Hormone receptor (HR)-positive, human epidermal growth factor receptor 2 (HER2)negative breast cancer is the most common breast cancer subtype, and endocrine therapy (ET) remains its therapeutic backbone. Although anti-estrogen therapies are usually effective initially, approximately $50 \%$ of $\mathrm{HR}+$ patients develop resistance to ET within their lifetime, ultimately leading to disease recurrence and limited clinical benefit. The recent addition of cyclin-dependent kinase 4 (CDK4) and CDK6 inhibitors (palbociclib, ribociclib, abemaciclib) to ET have remarkably improved the outcome of patients with HR+ advanced breast cancer (ABC) compared with anti-estrogens alone, by targeting the cell-cycle machinery and overcoming some aspects of endocrine resistance. However, 
which patients are the better candidates for these drugs, which are the main characteristics for a better selection of patients or if there are predictive biomarkers of response, is still unknown. In this review we reported the mechanism of action of CDK4/6 inhibitors as well as their potential mechanism of resistance, their implications in clinical practice and the forthcoming strategies to enhance their efficacy in improving survival and quality of life of patients affected with HR+, HER2-, ABC.

Keywords: CDK4/6 inhibitors; breast cancer; endocrine therapy (ET); advanced breast cancer (ABC); endocrine resistance

\section{Introduction}

Hormone receptor (HR)-positive, human epidermal growth factor receptor 2 (HER2)negative breast cancer is the most common breast cancer subtype, and endocrine therapy (ET) remains its therapeutic backbone. Although anti-estrogen therapies are usually effective initially, approximately $50 \%$ of $\mathrm{HR}+$ patients develop resistance to ET within their lifetime, ultimately leading to disease recurrence and limited clinical benefit [1]. The recent addition of cyclin-dependent kinase 4 (CDK4) and CDK6 inhibitors (palbociclib, ribociclib, abemaciclib) to ET have remarkably improved the outcome of patients with $\mathrm{HR}+$ advanced breast cancer $(\mathrm{ABC})$ compared with anti-estrogens alone, by targeting the cell-cycle machinery and overcoming some aspects of endocrine resistance.

\subsection{Mechanism of Endocrine Therapy Resistance}

Until now, three distinct pathways of regulation of estrogen receptor (ER) gene (ESR1) expression were thought to be mainly involved in breast cancer resistance to ET [2]: (i) Classic signaling: ligand-binding domain mutations in the ER that activates ESR1 expression (approximately $18 \%$ of endocrine-resistant HR+ breast cancers); (ii) Ligand independent signaling: ER can also be activated as a consequence of signaling events downstream of receptor tyrosine kinases (RTKs); (iii) Non-genomic mechanisms: signaling can be mediated by ER that is localized at the cell membrane or in the cytoplasm of breast cancer cells. A figure that summarizes all the described endocrine-resistance mechanisms was reported. (Figure 1)

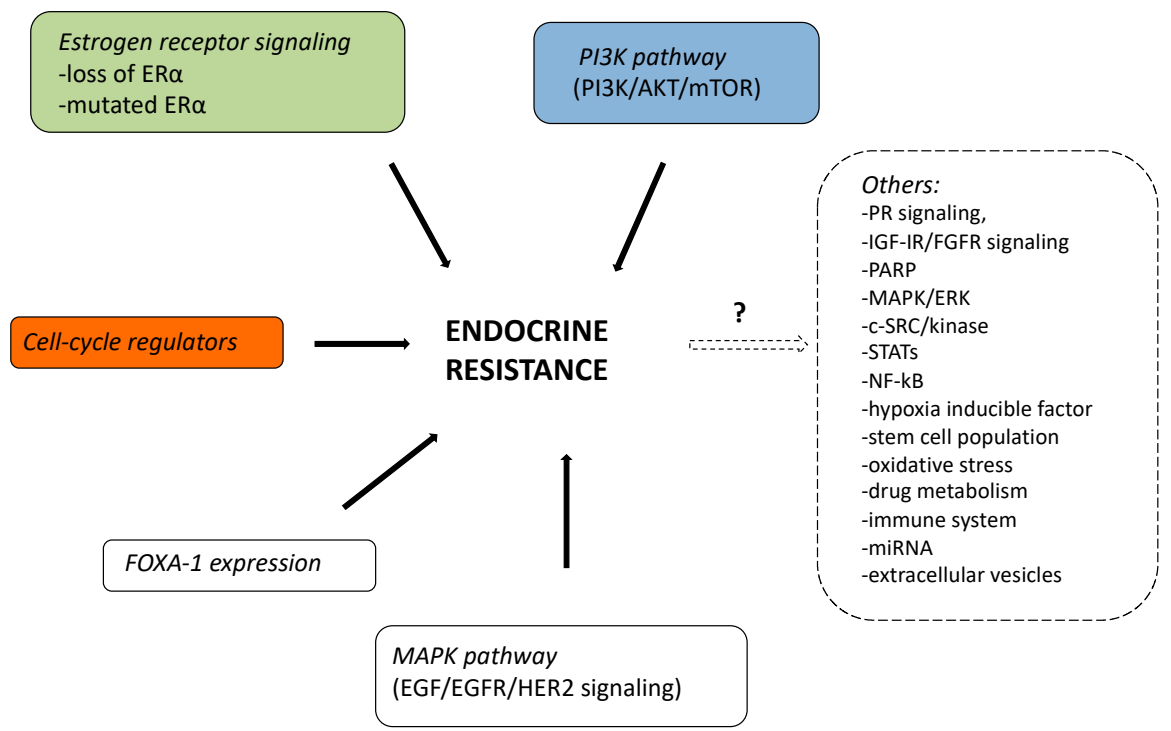

Figure 1. Possible mechanisms of endocrine resistance in summary. 


\subsubsection{Mutations of ER- $\alpha$}

$E R$ mutations are rare in primary tumors but appear to be reasonably frequent in the progression to endocrine resistance [3]. The spot mutations drive estrogen-independent transcriptional activity and cancer cell proliferation, leading to endocrine resistance [4].

\subsubsection{Loss of ER- $\alpha$}

Lack of $E R$ is one of the principal causes of de novo resistance to ET. The loss of $E R-\alpha$ expression can be achieved by epigenetic mechanisms such as methylation of CpG islands or histone deacetylase activity in the ESR1 promoter; DNA methyltransferase (DMNT) and histone deacetylase (HDAC) influence chromatin condensation regulating the ER gene expression [5].

In vitro experiments showed that DNMT1 inhibitors (Aza) and HDAC inhibitors (TSA) reduce chromatin condensation leading to ER expression in ER-negative breast cancer cells [6]. Moreover, AZA + TSA treatment inhibits tumor growth in mice inoculated with ER-negative breast cancer cells after ovarian ablation and restores sensitivity to tamoxifen [7].

\subsubsection{MAPK Pathway (EGF/EGFR/HER2 Signaling)}

Mutation in the MAPK pathway has been reported in approximately $13 \%$ of breast cancers [1]. In addition to the expected ESR1 hotspot mutations, ERBB2 and NF1 were the genes, mostly mutually exclusive, with the greatest difference in mutational frequency between pre- and post-hormonal therapy for HR + HER2 - breast cancers [1]. Tamoxifenresistant breast cancer cells (LTam) showed an hyperactivation of the HER/EGFR/Akt/ERK pathway. An in vitro study demonstrated that, by using lapatinib, a dual inhibitor of EGFR and HER2, tamoxifen sensitivity of LTam cells was restored [8].

\subsubsection{PI3K Pathway (PI3K/AKT/mTOR)}

Resistance to letrozole in breast cancer cells is associated with hyperactivation of $p 70 S 6 \mathrm{~K}$ and $A K T$, which are involved in the PI3K pathway. PI3K inhibitor (BEZ235, AEW541), mTOR inhibitor (RAD001), and EGFR/HER2 inhibitor (lapatinib) suppress proliferation of letrozole-resistant breast cancer cells [9]. PI3K inhibition enhances $E R$ function and the response to endocrine therapies. Indeed, the PI3K inhibitor alpelisib (BYL719) in combination with the ER inhibitor fulvestrant has profound antitumor activity both in vivo and in vitro [10].

\subsubsection{FOXA-1 Expression}

Foxa-1 is an essential protein for the transcriptional activity of both ER and androgen receptor (AR). The induction of FOXA-1 expression with doxycycline in breast cancer cells was directly related to a high level of expression of proliferation genes and inversely to estrogen sensitivity genes. Moreover, increased expression of FOXA1 contributes to tumor aggressiveness and endocrine resistance [11].

Other genomic and nongenomic mechanisms of resistance to ET are under investigation (eg, progesterone receptor signaling, IGF-IR, FGFR signaling, PARP, MAPK/ERK, c-SRC/KINASE, STATs, NF-kB, hypoxia inducible factor, stem cell population, oxidative stress, drug metabolism, immune system, miRNA, and extracellular vesicles) although the precise mechanisms remain largely unexplained. Complicating matters, some patients with $\mathrm{ABC}$ have distinct and coexisting mechanisms of resistance to ET in distinct tumor subclones that cannot be captured by a single biopsy of a metastatic site. Rizavi et al. [1] suggest that there was an emerging taxonomy of endocrine-resistant breast cancer, but some of these alterations were a consequence of selective therapeutic pressure and mechanisms of systemic therapy resistance. Therefore, to better define the complexity of endocrine resistance in HR+, HER- ABC, further genomic study of a large cohort of clinically phenotyped patients is needed. 


\subsubsection{Cell-Cycle Regulators and Endocrine Resistance}

Activation by D-type cyclin proteins leading to phosphorylation of retinoblastomaassociated protein and E2F protein-mediated transcription of cell-cycle genes, such as cyclins A and E, are critical for cell-cycle progression. Therefore, the action of cyclindependent kinases $4 / 6(\mathrm{CDK} 4 / 6)$ by regulating the transition from G1-to-S cell-cycle phase is crucial for normal and cancer cell proliferation [12].

Indeed, CDK4/ 6 inhibitors have shown significant preclinical activity in ER-positive breast cancer, especially when combined with anti-estrogen therapy. In an in vitro experiment, CDK4 inhibitor (PD-0332991) reduced cell tumor growth of fulvestrant-insensitive $\mathrm{ER}+$ cell lines and tumor growth of mice bearing an ER+ breast cancer cell line [13].

On transcriptome analysis, 58 tumor samples from letrozole-resistant patients were enriched for cell-cycle related genes. Treatment with palbociclib compared with fulvestrant significantly downregulated the expression of cell-cycle genes associated with letrozole resistance [14].

Abemaciclib is also a highly selective, reversible CDK $4 / 6$ inhibitor with the highest half maximal inhibitory concentrations of $2 \mathrm{nM}$ and $10 \mathrm{nM}$ for CDK4 and CDK6, respectively [15].

In addition, ribociclib showed remarkable preclinical efficacy in ER+BC mouse models by reducing tumor growth both as a single agent and in combination with letrozole or fulvestrant and with a PI3K inhibitor.

Although the three approved CDK4/6 inhibitors—-palbociclib, ribociclib, and abemaciclibseem to have essentially overlapping patterns of activity, as multikinase inhibitors, they could have many other mechanisms of action on several cellular populations other than tumor cells, particularly in the bone microenvironment. The extent to which these off-target events occur may also explain the difference in survival reported with the three different CDK4/ 6 inhibitors, but their significance in the overall treatment of disease is still not clear [16].

\subsection{Clinical Implications}

At the 4th ESO-ESMO international consensus, primary endocrine resistance was defined as "relapse while on the first 2 years of adjuvant ET, or PD within first 6 months of first-line ET for ABC, while on ET" and secondary endocrine resistance as "relapse while on adjuvant ET but after the first 2 years, or relapse within 12 months of completing adjuvant $\mathrm{ET}$, or $\mathrm{PD} \geq 6$ months after initiating ET for $\mathrm{ABC}$, while on ET". However, these definitions are subsequent to CDK4/ 6 inhibitors trials and limited to $67 \%$ consensus.

According to endocrine sensitivity/resistance, four main scenarios are represented among the phase 3 CDK4/6-based trials: (1) de novo metastatic disease; (2) late relapse; (3) early relapse; and (4) second line (Table 1). 
Table 1. CDK4/6 inhibitors phase 3 trials according to endocrine sensitivity/resistance patients representation and outcome results.

\begin{tabular}{|c|c|c|c|c|c|c|c|c|c|}
\hline \multirow{2}{*}{ Drug } & \multirow{2}{*}{ Trial } & \multirow{2}{*}{ Setting } & \multicolumn{4}{|c|}{ Endocrine Sensitivity/Resistance (\%) } & \multicolumn{2}{|l|}{ Efficacy } & \multirow[t]{2}{*}{ Adverse Events of Interest } \\
\hline & & & De Novo & Late Relapse & Early Relapse & Second Line & PFS (Months) & OS (Months) & \\
\hline \multirow[t]{3}{*}{ Ribociclib } & MONALEESA-2 [17] & First line & 34 & 64.7 & - & - & $\begin{array}{c}\text { RIBO + LET: } 25.3 \\
\text { PBO + LET: } 16.0 \\
(\mathrm{HR}, 0.56 ; 95 \% \text { CI, } 0.43-0.72 ; p<0.001)\end{array}$ & Immature & $\begin{array}{ll}- & \mathrm{G} \frac{3}{4} \text { neutropenia: } 62 \% \\
\text { - } & \text { Diarrhea: } 2.4 \% ; \\
\text { TE: } 0.6 \% ; \\
& \text { QTcF prolongation: } \\
& 3.6 \%\end{array}$ \\
\hline & MONALEESA-7 [18] & $\begin{array}{l}\text { First and second } \\
\text { line }\end{array}$ & 40 & 52.5 & - & $14($ after CT) & $\begin{array}{c}\text { RIBO + TAM/NSAI: } 23.8 \text { months } \\
\text { PBO + TAM/NSAI: } 13.0 \text { months } \\
\text { (HR, } 0.55 ; 95 \% \text { CI, } 0.44-0.69 ; p<0.0001)\end{array}$ & $\begin{array}{c}\mathrm{HR}, 0.712 ; 95 \% \mathrm{CI} \\
0.535-0.948 ; p=0.00973\end{array}$ & $\begin{array}{ll}\text { - } & \text { G3/4 neutropenia: } \\
& 60.6 \% \\
\text { - } & \text { Diarrhea: } 1 \% \\
\text { - } & \text { TE: NR } \\
\text { QTc prolongation: } 7 \%\end{array}$ \\
\hline & MONALEESA-3 [19] & $\begin{array}{l}\text { First and second } \\
\text { line }\end{array}$ & 20 & 29 & 28 & 20 & $\begin{array}{c}\text { RIB + FUL: } 20.5 \text { (33.6 in first line) } \\
\text { PBO + FUL: } 12.8 \text { (19.2 in first line) } \\
\text { (HR, 0.593; 95\% CI, 0.480-0.732; } \\
p<0.001)\end{array}$ & $\begin{array}{c}\mathrm{HR}, 0.724 ; 95 \% \mathrm{CI} \\
0.568-0.924 ; p=0.00455\end{array}$ & $\begin{array}{ll}- & \text { G 3/4 neutropenia: } \\
& \text { 53.4\% } \\
\text { D } & \text { Diarrhea: } 0.6 \% \\
\text { TE: NR } & \text { QTcF prolongation: } \\
& \text { 5.6\% }\end{array}$ \\
\hline \multirow[t]{2}{*}{ Abemaciclib } & MONARCH-3 [20] & First line & 41.2 & 58.8 & - & - & $\begin{array}{c}\text { ABE + NSAI: } 28.18 \text { months } \\
\text { PBO + NSAI: } 14.76 \text { months } \\
(\text { HR, 0.540; } 95 \% \text { CI, 0.418-0.698; } \\
p=0.000002)\end{array}$ & Immature & $\begin{array}{ll} & \text { G 3/4 neutropenia: } \\
& 23.9 \% \\
\text { - } & \text { Diarrhea: } 82.3 \% \\
\text { - } & \text { TE: } 4.9 \% \\
& \text { QTcF prolongation: } \\
& 0.3 \%\end{array}$ \\
\hline & MONARCH-2 [21] & Second line & - & - & 60 & 38 & $\begin{array}{c}\text { ABE + FUL: } 16.4 \\
\text { PBO + FUL: } 9.3 \\
(\text { HR, } 0.553 ; 95 \% \text { CI, } 0.449-0.681 ; \\
p<0.001)\end{array}$ & $\begin{array}{c}\text { HR, } 0.757 ; 95 \% \text { CI, } \\
0.606-0.945 ; p=0.0137\end{array}$ & $\begin{array}{ll} & \text { G 3/4 neutropenia: } \\
& 23.9 \% \\
\text { D } & \text { Diarrhea: } 82.3 \% \\
\text { - } & \text { TE: } 0.9 \% \\
& \text { QTcF prolongation: } \\
& 0.3 \%\end{array}$ \\
\hline \multirow[t]{2}{*}{ Palbociclib } & PALOMA-2 [22] & First line & 37.6 & 40.01 & - & - & $\begin{array}{c}\text { PAL + LET: } 24.8 \\
\text { PBO + LET: } 14.5 \\
(\mathrm{HR}, 0.58 ; 95 \% \mathrm{CI}, 0.46-0.72 ; p<0.001)\end{array}$ & Immature & $\begin{array}{ll}- & \text { G 3/4 neutropenia: } \\
& 66.4 \% \\
\text { - } & \text { Diarrhea: } 1.4 \% \\
\text { - } & \text { TE: } 0.9 \% \\
& \text { QTcF prolongation: } 0 \%\end{array}$ \\
\hline & PALOMA-3 [23-25] & Second line & - & - & 21 & 79 & $\begin{array}{c}\text { PAL + FUL: } 9.5 \\
\text { PBO + FUL: } 4.6 \\
(\mathrm{HR}, 0.46 ; 95 \% \text { CI, } 0.36-0.59 ; p<0.0001)\end{array}$ & $\begin{array}{c}\mathrm{HR}, 0.81 ; 95 \% \text { CI, } 0.64-1.03 \\
p=0.09\end{array}$ & $\begin{array}{ll}- & \text { G 3/4 neutropenia: } 62 \% \\
\text { Diarrhea: } 0 \% \\
\text { TE: } 1.7 \% \\
\text { QTcF prolongation: } \\
\\
<1 \%\end{array}$ \\
\hline
\end{tabular}

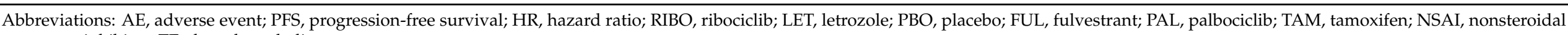
aromatase inhibitor; TE, thromboembolic event. 


\subsubsection{First Line}

According to the literature data, international clinical guidelines recommended ET as the preferred option for HR+, HER2 - ABC in as first-line therapy, even in the presence of visceral disease.

Chemotherapy is reserved for visceral crisis, defined as severe organ dysfunction and rapid progression of disease, or progression on multiple lines of ET. A recent metanalysis showed that no chemotherapy regimen with or without targeted therapy is significantly better than CDK4/ 6 inhibitors plus hormone therapies in terms of progression-free survival [26]. Thus, considering the significant improvement in the outcome of patients with HR+, HER2 - ABC with adjunct of CDK4/ 6 inhibitor to standard hormonal therapies compared with ET alone, the combinatorial strategy of CDK4/ 6 inhibitors and ET should be considered as the new standard of care in first- or second-line therapy (Table 1). A network meta-analysis, including patients treated with CDK4/6 inhibitors combined with aromatase inhibitors (AIs) or fulvestrant in comparison with AI or fulvestrant monotherapy, confirmed CDK4/6 inhibitors had similar efficacy when associated with an $\mathrm{AI}$ in the first-line treatment of $\mathrm{HR}+\mathrm{ABC}$, and were superior to either fulvestrant or AI monotherapy, regardless of any other patient or tumor characteristics [27].

In de novo patients, all the CDK4/ 6 inhibitors performed better than ET alone in terms of progression-free survival (PFS) (MONALEESA-2, hazard ratio, 0.45; MONALEESA-3, hazard ratio, 0.57; MONALEESA-7, hazard ratio, 0.43; MONARCH-3, hazard ratio, 0.54; PALOMA-2, hazard ratio, 0.67) [17-20,22]. The MONALEESA-7 trial was the only phase 3 trial to study CDK4/ 6 inhibitors as first-line therapy in a premenopausal population; the percentages of premenopausal patients studied with palbociclib and abemaciclib derived from the second-line trials, PALOMA-3 and MONARCH-2, were $20.7 \%$ and $16.1 \%$, respectively, where CDK4/ 6 inhibitors were combined with fulvestrant. The updated analysis of MONALEESA-7 showed that the addition of ribociclib to ET significantly prolonged overall survival (OS) compared with ET alone with an estimated OS at 42 months of $70.2 \%$ in the ribociclib group and $46.0 \%$ in the placebo group (hazard ratio, $0.71 ; p=0.00973$ ) [28]. On the basis of its innovative results, ribociclib plus ET (AI/TAM) with ovarian function suppression (OFS) was recently approved by the Italian Medicines Agency (AIFA), and thus it could be considered as the preferred first-line treatment option in premenopausal patients with HR+, HER2 - ABC. The overall response rate (ORR) was similar in MONALEESA-2 $(\mathrm{ORR}=52.7 \%)$, MONARCH-3 $(\mathrm{ORR}=59.2 \%)$, and PALOMA $2(\mathrm{ORR}=55.3 \%)$. However, with a median PFS of 33.6 months rather than 22-28 months with palbociclib or with abemaciclib plus AI, and a relative risk reduction in death of $28 \%$ in the first-line setting of MONALEESA-3, ribociclib plus fulvestrant seems to be the preferred first-line treatment option in postmenopausal patients [19]. Moreover, whereas the data on OS for palbociclib and abemaciclib are still immature or are from real-world data of retrospective studies [29,30], the data on OS with ribociclib come directly from phase 3 trials [18,19].

The three CDK4/ 6 inhibitors reported a good toxicity profile; there was higher incidence of grade 3-4 neutropenia with both ribociclib and palbociclib, and diarrhea and abdominal pain with abemaciclib (Table 1). QTcF prolongation with ribociclib occurred in no more than 23 patients (7\% of cases) in the MONALEESA-7 trial. However, the percentage of cases of QT prolongation was even lower in clinical practice. Dose reductions due to adverse events was reported in $54.5 \%, 33.1 \%$, and $31 \%$ of cases in MONALEESA-2, MONALEESA-3, and MONALEESA-7, without any significant impact on PFS [17-19]. Thus, if toxicity occurs, the dosage of ribociclib can be reduces without affecting its efficacy. Both MONARCH [20,21] and PALOMA-3 [24] studies showed no difference in PFS for patients who had the dose reduced due to any adverse events compared with those who did not.

However, the clinical scenario could be much more complex according to potential drug-drug interactions (DDIs) in patients with breast cancer treated with CDK4/6 inhibitors; DDIs may occur in patients who take polypharmacy [31]. Therefore, better knowledge of how patient metabolism and DDIs could affect both the efficacy and safety 
of CDK4/ 6 inhibitors should always be considered to maximize the personalization of cancer care in patients with ABC (Figure 2). Indeed, any physician should know that concomitant medications (e.g., proton pump inhibitors and corticosteroids), pharmacogenetic profile, and pathophysiological conditions could influence absorption, distribution, metabolism, and elimination pharmacokinetics. A personalized therapeutic approach taking into consideration all these factors potentially contributing to an altered pharmacokinetic/pharmacodynamic profile could better drive safe and effective clinical use of third generation CDK4/ 6 inhibitors [32]. According to the application of precision medicine in the management of cancer treatment, new software, Drug-PIN, which combines data regarding DDIs and the pharmacogenomic profile of cancer patients, is under investigation at our institution [33].

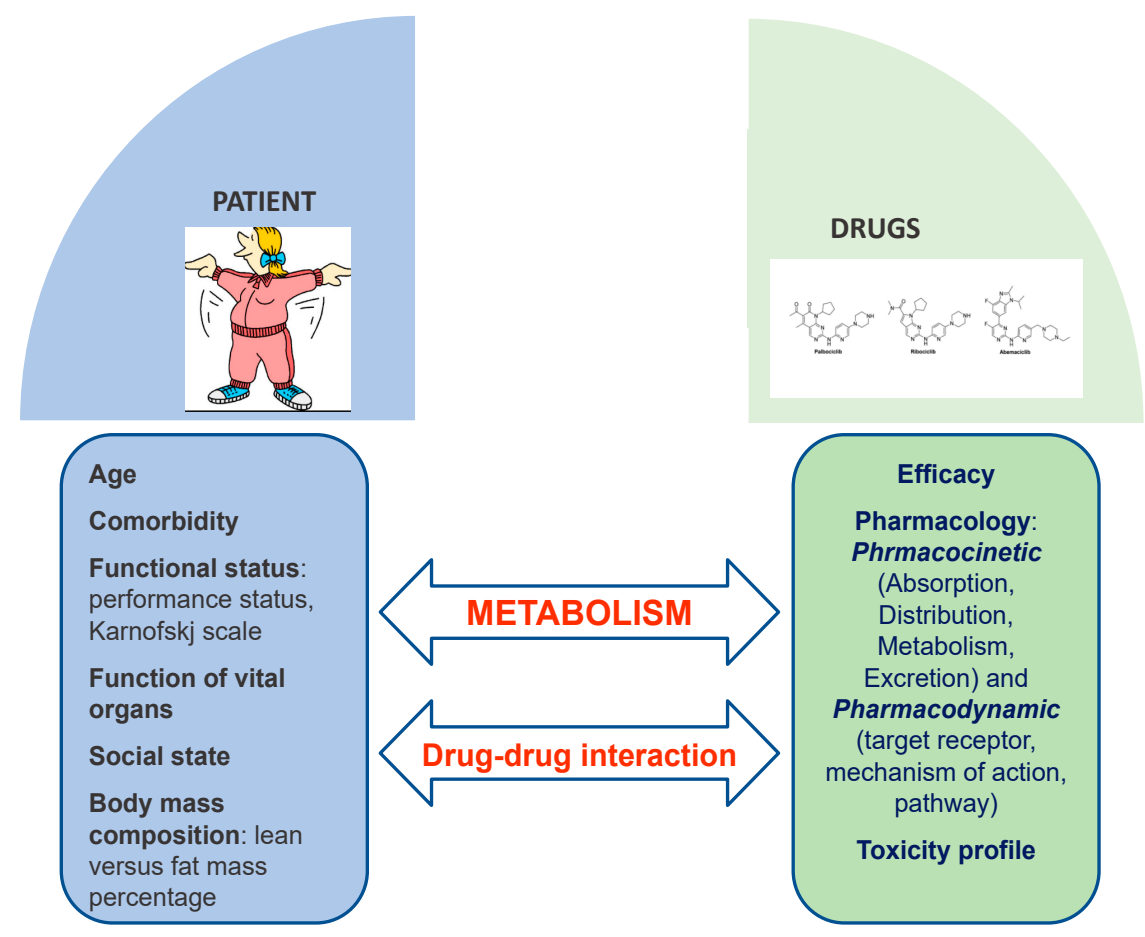

Figure 2. The complexity of patient metabolism and potential drug-drug-interactions.

\subsubsection{Second Line and Early Relapse}

According to the Associazione Italiana di Oncologia Medica (AIOM) guidelines, "early relapse" is defined as aggressive disease that presents itself with a short disease-free interval from the adjuvant therapy (progression during or within 12 months from the end of adjuvant ET); this it is slightly different from the European Society for Medical Oncology definitions of primary and secondary resistance mentioned earlier, but it is the same definition in the three different trials:

MONALEESA-3: Patients who had a relapse during or within 12 months after completion of adjuvant or neoadjuvant ET.

MONARCH-2: Patients were required to have progressive disease while receiving neoadjuvant or adjuvant ET, within 12 months from the end of adjuvant ET.

PALOMA-3: Disease relapse or progression had to occur while on or within 12 months of completion of adjuvant therapy irrespective of menopausal status.

All these trials enrolled patients who experienced progression after mono-ET (with tamoxifen or aromatase inhibitor) and their primary endpoint was the difference in survival between CDK4/ 6 inhibitor plus fulvestrant versus fulvestrant plus placebo.

With the except of MONALEESA-3, both MONARCH-2, and PALOMA-3 included pre- and postmenopausal women $[19,21,23,24]$. According to 4th ESO-ESMO International Consensus Guidelines for Advanced Breast Cancer (ABC 4) [34], young women with 
$\mathrm{ER}+\mathrm{ABC}$ should have adequate ovarian suppression or ablation (OFS/OFA) and then be treated in the same way as postmenopausal women with endocrine agents with or without targeted therapies. Since the first step is to render the patient postmenopausal, all treatment recommendations should be common to both post and premenopausal patients. Therefore, patients should be informed on the options of ovarian ablation by laparoscopic bilateral oophorectomy so that it provides definitive estrogen suppression and contraception, avoids potential initial tumor flare with a luteinizing hormone-releasing hormone agonist, and may increase eligibility for clinical trials. However, no significant difference in median OS was found between premenopausal or perimenopausal patients included in PALOMA-3 (108 patients [21\%], hazard ratio, 1.07; 95\% confidence interval [CI], 0.61-1.86) [35] and MONARCH-2 (114 patients [17\%], hazard ratio, 0.68; 95\% CI, 0.37-1.25) [21] Otherwise, median PFS and ORR were significantly higher with ribociclib than with placebo in the subgroup analysis of premenopausal patients treated previously with chemotherapy for ABC included in the MONALEESA-7 trial [36].

In the indirect comparison of the populations enrolled in the three phase 3 trials with CDK4/6 inhibitors and fulvestrant (Table 2), the PFS data were similar but the results on OS were slightly different, probably not only due to the intrinsic pharmacokinetic differences between ribociclib, palbociclib, and abemaciclib [31] but also due to the different characteristics of the patient populations (Table 2).

Table 2. Phase 3 trials of CDK4/6 inhibitors that included patients(n) in second-line and early relapse settings, in respect to the total populations enrolled $(\mathrm{N})$.

\begin{tabular}{|c|c|c|c|c|c|c|}
\hline Trial & Population & $\mathbf{n} / \mathbf{N}$ & Treatment & PFS (Months) & OS (Months) & ORR (\%) \\
\hline MONALEESA-3 & $\begin{array}{l}\text { - } \quad \text { Postmenopausal women and } \\
\text { men; } \\
\text { - Second-line/early relapse } \\
\text { subgroup }\end{array}$ & $346 / 726$ & $\begin{array}{l}\text { Ribociclib plus } \\
\text { fulvestrant versus } \\
\text { placebo + fulvestrant }\end{array}$ & $14.6(\mathrm{HR}, 0.57)$ & $\begin{array}{l}40.2(\mathrm{HR}, \\
0.73)\end{array}$ & 40.9 \\
\hline MONALEESA-7 & $\begin{array}{l}\text { - } \quad \text { Premenopausal women; } \\
\text { Early relapse and previous } \\
\text { first line of CT }\end{array}$ & $94 / 672$ & $\begin{array}{l}\text { Ribociclib plus ET } \\
\text { plus goserelin versus } \\
\text { placebo }+ \text { ET and } \\
\text { goserelin }\end{array}$ & 16.6 (HR 0.54) & NR (HR 0.67) & 26 \\
\hline MONARCH-2 & $\begin{array}{l}\text { - } \quad \text { Pre/postmenopausal women } \\
\text { and men; } \\
\text { - } \quad \text { Second line/early relapse; } \\
\text { - } \quad \begin{array}{l}\text { Primary and secondary ET } \\
\text { resistance }\end{array}\end{array}$ & 669 & $\begin{array}{c}\text { Abemaciclib plus } \\
\text { fulvestrant versus } \\
\text { placebo + fulvestrant }\end{array}$ & $16.4(\mathrm{HR}, 0.55)$ & $\begin{array}{c}46.7 \\
(\mathrm{HR} 0.75)\end{array}$ & 48.1 \\
\hline PALOMA-3 & 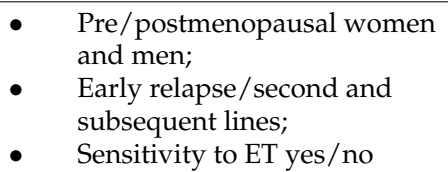 & 521 & $\begin{array}{l}\text { Palbociclib plus } \\
\text { fulvestrant versus } \\
\text { placebo + fulvestrant }\end{array}$ & $11.2(\mathrm{HR}, 0.50)$ & $\begin{array}{c}34.9(\mathrm{HR}, 0.81 \\
\mathrm{NS}, p=0.09)\end{array}$ & 25 \\
\hline
\end{tabular}

Abbreviations: PFS, progression-free survival; OS, overall survival; ORR, overall response rate; HR, hazard ratio; ET, endocrine therapy;

NS, not significant.

For example, PALOMA-3 included patients pretreated with more than one line of therapy compared with patients included in MONALEESA-3 and MONARCH-2, where only one previous line of ET was allowed [19,21,23].

In patients with previous ET, the median PFS was significantly better in the CDK4/ 6 arm in MONALEESA-3, MONARCH-2, and PALOMA-3. However, in postmenopausal women pretreated with ET and postmenopausal women with early relapse, the median OS reached 40.2 months in the ribociclib group compared with 32.5 months in the placebo group (hazard ratio, $0.73 ; 95 \%$ CI, 0.53-1.00) [19].

In the MONARCH-2 early relapse group, median OS was improved by 9.4 months, with a median OS of 46.7 months in the abemaciclib arm and 37.3 months in the placebo arm (hazard ratio, $0.757 ; 95 \%$ CI, 0.606-0.945; $p=0.01$ ) [21]. However, earlier separation of the curves and a numerically larger effect were observed in patients with primary ET resistance (hazard ratio, 0.686 ; 95\% CI, $0.451-1.043$ ) compared with patients with secondary 
ET resistance (hazard ratio, $0.787 ; 95 \%$ CI, 0.606-1.021) but no statistically significant interaction was observed.

In the PALOMA-3 trial, the median OS was not statistically significant (34.9 months in the palbociclib-fulvestrant group and 28.0 months in the placebo-fulvestrant group; HR, $0.81 ; 95 \%$ CI, 0.64-1.03; $p=0.09$ ) [24]. However, women were enrolled regardless of menopausal status and including patients treated with more than one line of previous ET. The difference in median OS was statistically significant (39.7 months in the palbociclib group and 29.7 months in the placebo group; hazard ratio, 0.72) only among those patients with documented sensitivity (secondary resistance) to previous ET.

These results highlight the following considerations: (1) ribociclib seems to perform better in an acquired resistance setting; (2) abemaciclib seems to perform better in the primary endocrine resistance setting; (3) despite the promising results with palbociclib in pretreated patients, the data on OS are still inconclusive. Overall, the adjunct of CDK4/6 inhibitors in patients with visceral disease versus patients who did not have visceral metastasis was beneficial in the three trials.

Finally, the retrospective analysis of second-line treatment in patients who progressed on CDK4/ 6 inhibitors as first-line therapy also deserves mention. In a recent study among patients who progressed on palbociclib $(n=104)$, the most frequent next-line treatment was capecitabine $(n=21)$, followed by eribulin ( $n=16)$, nab-paclitaxel $(n=15)$, and exemestane plus everolimus $(n=12)$. The median PFS with hormonal therapy or combinations $(n=32)$ after first-, second-, and subsequent-line palbociclib was 17.0, 9.3, and 4.2 months, respectively $(p=0.04)$; whereas the median PFS with chemotherapy $(\mathrm{n}=70)$ was not reached at 4.7 and 4.1 months in patients after first-, second-, or subsequent-line therapy with palbociclib $(p=0.56)$. The authors concluded that in real-world practice, hormone therapy alone or in combination with targeted agents remains an effective option after palbociclib progression [37].

In a retrospective analysis of patients treated according to the BOLERO-2 trial with everolimus plus exemestane, 17 patients had undergone previous CDK4/6 inhibitor therapy and 16 had not. In this study, there was no significant difference in PFS (median, 5.7 months versus 4.7 months, $p=0.890$ ) or OS (median, 17.8 months versus 11.4 months, $p=0.177$ ) between patients who received previous therapy with CDK4/ 6 inhibitors and those who did not, respectively. Therefore, the combination of everolimus plus exemestane remains a good option in advanced lines of treatment [38].

Moreover, a retrospective study of 58 patients with HR+/HER2 - ABC who received abemaciclib after disease progression on palbociclib was conducted. In this study, 20 patients $(34 \%)$ received sequential courses of therapy, and 38 patients $(66 \%)$ had at least one intervening non-CDK4/6 inhibitor regimen. Fourteen patients $(24 \%)$ received abemaciclib monotherapy and 44 patients $(76 \%)$ received abemaciclib in combination with an anti-estrogen, including fulvestrant (52\%), an aromatase inhibitor $(22 \%)$, and tamoxifen $(2 \%)$ [39]. In this analysis, 20 patients $(34 \%)$ had early disease progression (duration $<90$ days), whereas 21 patients $(36 \%)$ had treatment duration exceeding 6 months, including 10 who remained on treatment at the interim analysis (range, 181-413 days). The median PFS was 5.8 months (95\% CI, 3.4-8.0). Although the results are not conclusive, this is the first multicenter experience to demonstrate that a substantial proportion of patients continue to maintain clinical benefit with another CDK4/ 6 inhibitor after previous CDK $4 / 6$ inhibitor, highlighting the potential for their use after CDK $4 / 6$ blockade.

\section{Future Perspectives}

It is not currently known how the different combinations of ET and targeted agents compare with each other, or with single-agent chemotherapy, or which are the best candidates as CDK4/ 6 inhibitors. Therefore, a better understanding of the molecular pathways that could lead to resistance to CDK4/ 6 inhibitor is urgently required.

With this aim, several mechanisms of resistance to CDK4/ 6 inhibitors and potential biomarkers are under investigation [40]. 
Here, we present selected potential mechanisms investigated for resistance to CDK4/6 inhibitors, dividing them in two groups: (1) cell-cycle-specific mechanisms (loss of retinoblastoma [RB]; CCND1 amplification and/or loss of p16; CCNE1/2 amplification/overexpression; CDK4/6 amplification/overexpression) [41-43] and (2) cell-cycle-nonspecific mechanisms (PIK3CA pathway activation; FGFR pathway activation; mouse double minute 2 homolog (MDM2) overexpression; ESR1 expression and mutation; PD-1 expression; thymidine kinase-1 (TK1); FAT1 loss [41]; autophagy activation [44]). A summary of the main mechanisms potentially implicated in the resistance to CDK4/ 6 inhibitors is reported in Figure 3.

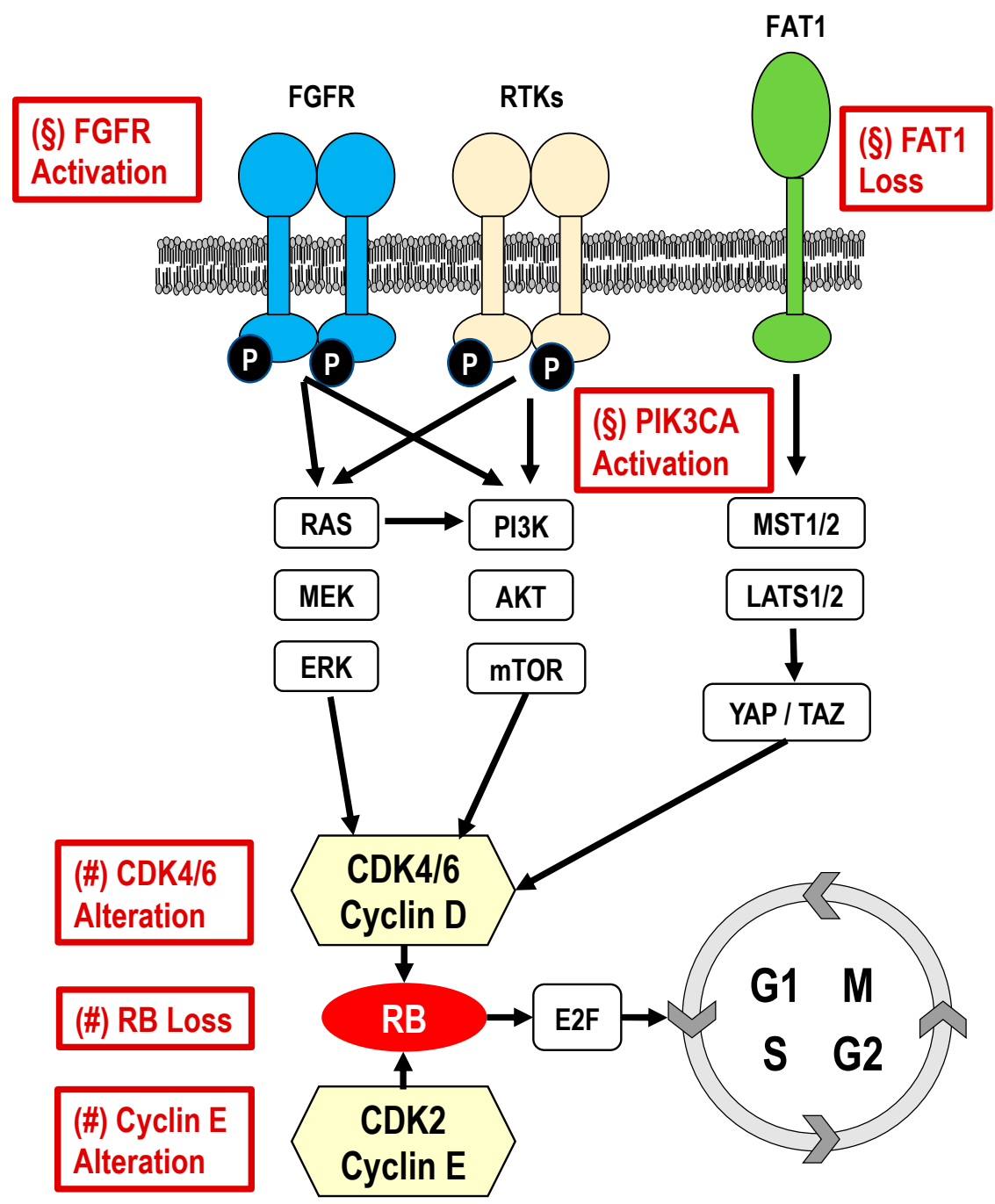

Figure 3. Summary of the main mechanisms potentially implicated in the resistance to CDK $4 / 6$ inhibitors: (§) Cell cycle-non-specific mechanisms; (\#) Cell cycle-specific mechanisms.

\subsection{Cell-cycle-Specific Mechanisms of Resistance to CDK4/6i}

- RB loss

$\mathrm{RB}$, a tumor suppressor, represents the main target of CDK4/6. Loss of RB emerged in preclinical studies as a driver of resistance to CDK4/6 inhibitors. The incidence of loss of $\mathrm{RB}$ in ER+ breast cancer is low $(<5 \%)$; in the PALOMA-3 study, polyclonal RB1 mutations were identified in $4.7 \%$ of patients (palbociclib arm). No significant interaction was found between treatment and expression levels of RB1 (and CDK4/6, cyclin D1) [24].

In the PALOMA-2 study no interaction was found between treatment and RB detected by immunohistochemistry, fluorescence in situ hybridization, or gene expression analysis (tumor samples) [45]. 
Total RB expression as assessed by immunohistochemistry was positive in $90.9 \%$ and negative in $9.1 \%$ of patients. Exploratory assessments of PFS by RB1 gene using this approach revealed a consistent benefit with palbociclib plus letrozole (RB-positive tumors: hazard ratio, $0.543 ; p<0.0001$ in favor of palbociclib) with no evidence of benefit with palbociclib in truly RB-null tumors (RB-negative tumors: hazard ratio, $0.868 ; p=0.698$ ), but this is clearly limited by the small number of patients in this cohort).

- $\quad$ CCND1 amplification/p16 loss

CCND1 amplification (around 15\% of breast cancers) and loss of p16 ${ }^{\mathrm{INK} 4 \mathrm{~A}}$ (a tumor suppressor of cyclin D1) have been hypothesized as reasonable factors of CDK4/6 inhibitors resistance. PALOMA-1 study failed to show any significant difference in PFS in patients with a loss of p16 or CCND1 amplification compared with unselected patients [22]. Moreover, expression levels of cyclin D1 were not associated with benefit from palbociclib in PALOMA-3 [24] and PALOMA-2 studies (also for p16 loss) [45].

\section{- CCNE1/2 amplification/overexpression}

CCNE1, the gene encoding cyclin E1, seems to be upregulated in preclinical models with resistance to CDK4/6 inhibitors [46]. However, in MONALEESA-2 trial, the mRNA expression analysis of tumor samples obtained from 391 of 668 randomized patients showed that the addition of ribociclib to letrozole provided a PFS benefit regardless of expression of CCNE1 [17]. Also, the analysis conducted in PALOMA-2 failed to demonstrate an association between CCNE1/2 expression (by immunochemistry, fluorescence in situ hybridization, or gene expression analysis) and benefit from palbociclib [45].

In PALOMA-3 study, tumor tissue mRNA profiling of 302 patients (from 521 randomized patients) was performed [35]. Although all biomarker groups derived benefit from palbociclib, those with low tumor CCNE1 expression had a greater response (median PFS with palbociclib plus fulvestrant versus fulvestrant was 14.1 months versus 4.8 months) than those with high CCNE1 expression (7.6 months versus 4.0; respectively)]. The predictive power of CCNE1 mRNA seems to be stronger in metastatic biopsies (interaction $p<0.001$ ) than archived primary biopsy samples (interaction $p=0.09$ ) [35]. Similar results were reported in the MONARCH-2 study [47].

- $\quad C D K 4 / 6$ amplification/overxpression

CDK4 and CDK6 overexpression was reported to promote resistance to CDK4/6 inhibitors in preclinical models. With regard to the clinical setting, in the PALOMA-2 trial, CDK4 expression levels predicted resistance to placebo plus letrozole but not to palbociclib plus letrozole [45]. In the letrozole arm, high levels of CDK4 mRNA were associated with more rapid progression. CDK6 expression did not have a similar effect (lower expression: hazard ratio, 0.596; higher expression: hazard ratio, 0.592).

In MONALEESA-2 study, the benefit of addition of ribociclib to letrozole seems to be slightly greater in patients with high versus low expression of cell-cycle-control genes (hazard ratio, 0.45 versus 0.66 ) [17]. In the placebo arm, the median PFS was shorter in patients with high expression of cell-cycle-control genes compared with low expression. The cell-cycle-control genes analyzed in this trial were CCNA2, CCND1, CCND2, CCND3, CCNE1, CDK2, CDK4, CDK6, CDKN1A, CDKN1B, CDKN2A, CDKN2B, CDKN2C, RB1, E2F1, E2F3, TFDP1, and TP53.

\subsection{Cell-cycle-Nonspecific Mechanisms of Resistance to CDK4/6 Inhibitors}

- PIK3CA pathway activation

In the MONALEESA-7 trial, circulating tumor DNA (ctDNA) sequencing analysis performed on 565 patients (from 672 patients randomized) showed PIK3CA mutations in $28 \%$ of patients [48]. The median PFS benefit with ribociclib was numerically greater in patients with wild-type PIK3CA than mutated PIK3CA, but the interaction test was not statistically significant. Similarly, the biomarker analysis of baseline ctDNA in MONALEESA-3 and 
MONARCH-2 studies demonstrated consistent benefit from ribociclib and abemaciclib, respectively, irrespective of PIK3CA status [49,50].

In MONALEESA-2 study, mRNA expression data from baseline tumor samples of the PI3K pathway genes ( $A K T 1, A K T 2, P I K 3 C A$, and $P T E N)$ suggested that ribociclib prolonged PFS regardless of PIK3CA gene pathway expression (high versus low) [17].

In PALOMA-3 trial, baseline plasma samples of 395 patients $(76 \%$ of randomized patients) were available for ctDNA analysis. PIK3CA mutations were detected in ctDNA of 129 patients (33\%) with no significant association observed with outcome [25]. The ctDNA sequencing analysis was performed on 195 patients (comparing baseline and endof-treatment status). At baseline, 39 PIK3CA variants were found in $19.0 \%$ of patients; at the end of treatment, there were 55 PIK3CA variants in $26.7 \%$ of patients. Therefore, $7.7 \%$ of patients acquired PIK3CA mutations during treatment. However, the proportion of patients acquiring newly detectable PIK3CA mutations did not differ between the treatment groups [51]. Thus, it cannot be concluded that PIK3CA is clearly a significant predictive biomarker of response o resistance to CDK4/ 6 inhibitors.

Similarly, biomarker analysis in MONALEESA-3 study demonstrated consistent benefit from ribociclib plus fulvestrant, irrespective of PIK3CA alteration status, as detected in baseline ctDNA.

\section{- FGFR pathway activation}

In vitro experiments in ER+ breast cancer cells suggested that FGFR/ FGF pathway alterations are associated with fulvestrant resistance as well as cross-resistance to Palbociclib [52]. In PALOMA-2, tumors with increased expression of FGFR2 appeared to be associated with greater gain in PFS from the combination of palbociclib plus letrozole (even though the interaction test was not statistically significant) [45].

Moreover, the FGFR signaling pathway seems to have a potential prognostic role. In MONALEESA-2, ctDNA analysis showed that patients with FGFR1 amplification (5\%) had a shorter PFS compared with patients with wild-type FGFR1 [53].

Similarly, in PALOMA-3, FGFR1 amplification (ctDNA) identified patients at risk of early disease progression [54].

- $\quad M D M 2$ overexpression

The MDM2 downregulates p53 activity inhibiting the cellular senescence. The interruption of the senescence pathway, induced by the MDM2 overexpression, is supposed to be a mechanism of resistance to CDK4/ 6 inhibitors. In preclinical models, the combination of MDM2 and CDK4/6 inhibitors showed a synergistic effect [55]. In this regard, MDM2 inhibitors may overcome resistance to CDK4/ 6 inhibitors [56].

- ESR1 expression and mutation

The role of ESR1 expression and mutation in patients receiving ER targeted therapy seems to be mainly prognostic. In MONALEESA-2, benefit from the addition of ribociclib seems to be greater in patients with high versus low ESR1 expression. However, there was a trend for longer PFS with high ESR1 expression in both arms [17]. Similar to the PALOMA-2 study, high ESR1 expression levels were associated with longer PFS in both arms [45].

In PALOMA-3, the benefit from palbociclib was seen despite the ESR1 mutation status (interaction $p=0.74$ ) [51]. Similar results were found in the MONARCH-2 study [50]. Thus, we cannot conclude that ESR1 is a predictive factor for CDK4/ 6 inhibitors response or resistance.

- $\quad P D-1$ expression

In PALOMA-2 study, lower PD-1 levels were associated with greater benefit with palbociclib plus letrozole [45]. Therefore, the PD-1 signaling pathway could be associated with reduced benefit in PFS from the addition of CDK4/ 6 inhibitors to ET. Ongoing studies are now evaluating immune checkpoint inhibitors targeting PD-1 in combination with CDK4/6 inhibitors. 


\section{- $\quad$ Thymidine kinase-1 (TK1)}

Another useful factor as a prognostic biomarker of sensitivity or early response to ET is TK1, an enzyme in the pyrimidine salvage pathway that plays a crucial role in DNA synthesis/cell proliferation. In primary breast cancer tissue, high TK1 levels and activity (TKa) correlate with a poor prognosis. A pilot study of patients treated with ET showed that those with low baseline levels of plasma TKa had a better median PFS than those with high baseline levels [57]. In addition, preclinical studies suggest TKa as an early marker of proliferative inhibition in response to palbociclib [58].

\section{- $\quad$ FAT1 loss}

FAT1 is a tumor suppressor gene, mutated in many cancers. A genomic analysis of 348 $\mathrm{ER}+$ breast cancers treated with CDK4/ 6 inhibitors showed that loss of FAT1 (or RB1) is associated with clinical resistance to these drugs [59]. Indeed, loss of FAT1 increases CDK6 expression via the Hippo pathway, reducing sensitivity to CDK4/6 inhibitors.

\section{- Autophagy activation}

Preclinical evidence suggests that autophagy activation may be implicated in resistance to CDK4/ 6 inhibitors, given that the cell cycle arrest induced by these inhibitors can be reversed by autophagy. Therefore, the inhibition of autophagy may increase the efficacy of CDK4/ 6 inhibitors and may contribute to overcome resistance to these drugs [60].

\subsection{Other Potential Mechanism of Resistance}

Finally, in the ongoing BIOITALEE study, the primary objectives were to identify ctDNA alterations, their evolution at different time points of therapy, and their possible association with clinical outcome [61].

The preliminary analysis reported several tumor molecular alterations at baseline and their correlation with clinical features and outcome. In detail, copy number gains of FGFR1-2-3 were more frequent in patients with visceral metastases; MYC gain or alterations in the ER nuclear function pathway were more frequent in patients with progesterone- and Ki67 $\geq 14 \%$ breast tumors. MYC gain, TP53 mutations, and alterations in the HER and CDK4/ 6 pathways were associated with disease progression at the first tumor evaluation $(10 \%)$, suggesting that they may be potential markers of intrinsic resistance to ribociclib and letrozole.

\subsection{Strategies after CDK4/6 Inhibitor Progression and New Therapeutic Combinations}

New treatment options at progression on a CDK4/6 inhibitor are emerging (Tables 3 and 4).

Table 3. Ongoing studies based on CDK4/6 inhibitors beyond progression.

\begin{tabular}{cccc}
\hline Trial & Phase & Study Arms & Previous CDK4/6 \\
\hline $\begin{array}{c}\text { MAINTAIN } \\
\text { (NCT02632045) }\end{array}$ & 2 & $\begin{array}{c}\text { Ribociclib + fulvestrant versus } \\
\text { placebo + fulvestrant }\end{array}$ & AI + palbociclib/ribociclib \\
\hline NCT02738866 & 2 & Palbociclib + fulvestrant & Palbociclib + AI \\
PACE (NCT03147287) & 2 & $\begin{array}{c}\text { Fulvestrant versus } \\
\text { fulvestrant + palbociclib } \\
\text { versus } \pm \text { avelumab }\end{array}$ & CDK4/6 inhibitor-based regimen \\
\hline NCT02871791 & $\frac{1}{2}$ & Palbociclib + everolimus + exemestane & CDK4/6 inhibitor-based regimen \\
\hline TRINITI-1 (NCT02732119) & $1 / 2$ & Ribociclib + everolimus + exemestane & CDK4/6 inhibitor-based regimen \\
\hline NCT01857193 & $1 \mathrm{~B}$ & $\begin{array}{c}\text { Ribociclib + exemestane } \\
\text { versus } \pm \text { everolimus }\end{array}$ & $\begin{array}{c}\text { Naive or refractory to } \\
\text { CDK4/6-inhibitor }\end{array}$ \\
\hline PALMIRA (NCT03809988) & 2 & Palbociclib + ET & $\begin{array}{c}\text { Had clinical benefits with } \\
\text { palbociclib + ET in first line }\end{array}$ \\
\hline
\end{tabular}

Abbreviations: AI, aromatase inhibitor; ET, endocrine therapy. 
Table 4. New agents after CDK4/6 inhibitor progression.

\begin{tabular}{|c|c|c|c|}
\hline Trial & Phase & Study Arms & Previous CDK4/6 \\
\hline \multicolumn{4}{|c|}{ CDK7 inhibitor after CDK4/6 inhibitor progression } \\
\hline NCT03134638 & 1 & SY-1365 + fulvestrant & CDK inhibitor + AI \\
\hline NCT03363893 & 1 & CT-7001 + fulvestrant & CDK inhibitor \\
\hline \multicolumn{4}{|c|}{ CDK2 inhibitor after CDK4/6 inhibitor progression } \\
\hline NCT03519178 & $1 / 2 \mathrm{~A}$ & PF-06873600 versus $\pm \mathrm{ET}$ & CDK inhibitor + ET \\
\hline \multicolumn{4}{|c|}{ Selective estrogen receptor downregulator (SERD) (elacestrant) after CDK4/6 inhibitor progression } \\
\hline $\begin{array}{c}\text { EMERALD } \\
\text { (NCT03778931) }\end{array}$ & 3 & Elacestrant & CDK inhibitor $+\mathrm{AI}$ or fulvestrant \\
\hline \multicolumn{4}{|c|}{ BCL-2 inhibitor (venetoclax) afterCDK4/6 inhibitor progression } \\
\hline $\begin{array}{c}\text { VERONICA } \\
\text { (NCT03519178) }\end{array}$ & 2 & Venetoclax + fulvestrant & CDK inhibitor-based regimen \\
\hline \multicolumn{4}{|c|}{ Fibroblast growth factor receptor (FGFR) inhibitor after CDK4/6 inhibitor progression } \\
\hline NCT03238196 & 1 & Fulvestrant + palbociclib + erdafitinib & Previous palbociclib allowed \\
\hline \multicolumn{4}{|c|}{ Immune checkpoint inhibitor after CDK4/6 inhibitor progression } \\
\hline PACE (NCT03147287) & 2 & $\begin{array}{l}\text { Fulvestrant versus fulvestrant }+ \\
\text { palbociclib versus } \pm \text { avelumab }\end{array}$ & CDK4/6 inhibitor-based regimen \\
\hline NCT0329469 & 1 & Fulvestrant + ribociclib + PDR001 & Not specified \\
\hline $\begin{array}{l}\text { MORPHEUS HR+BC } \\
\quad(\text { NCT03280563) }\end{array}$ & $1 / 2$ & $\begin{array}{c}\text { Fulvestrant } \\
\text { Atezolizumab + entinostat } \\
\text { Atezolizumab + fulvestrant } \\
\text { Atezolizumab + ipatasertib } \\
\text { Atezolizumab + ipatasertib + fulvestrant } \\
\text { Atezolizumab + bevacizumab + ET } \\
\text { Atezolizumab + abemaciclib + fulvestrant }\end{array}$ & CDK4/6 inhibitor in first or second line \\
\hline
\end{tabular}

Abbreviations: AI, aromatase inhibitor; ET, endocrine therapy.

The main strategies can be summarized in four groups: (1) maintain the CDK4/6 inhibitor and switch ET; (2) maintain ET and switch to another CDK4/6 inhibitor or another targeted agent; (3) maintain ET and CDK4/ 6 inhibitor + target a collateral pathway; (4) new agents.

In preliminary analysis of the phase $1 / 2$ TRINTI- 1 study in men and postmenopausal women with HR+, HER2 - locally advanced or metastatic breast cancer following progression on a CDK4/ 6 inhibitor, triplet therapy with ribociclib in combination with everolimus + exemestane demonstrated $39 \%$ clinical benefit within 24 weeks [48]. Thus, TRINITI-1 met its primary efficacy endpoint and is the first trial to demonstrate both activity and tolerability of continuous triplet therapy with ET + mTORi + CDK4/6.

Around $40 \%$ of patients with HR+, HER2- ABC present an activating tumor mutation of PIK3CA. On the basis of the phase 3 SOLAR-1 study, alpelisib + fulvestrant is a potential new treatment option for patients with PIK3CA-mutant HR+, HER2- ABC who have progressed on previous ET (with/without a CDK4/6 inhibitor). In patients with PIK3CAmutant disease, median PFS was 11.0 months versus 5.7 months in wild-type patients (hazard ratio, $0.65 ; p=0.00065$ ) [62].

However, alpelisib was recently approved in combination with fulvestrant for the treatment of postmenopausal women and men with HR+, HER2 - ABC with a PIK3CA mutation after disease progression following ET as monotherapy. Therefore, the choice for patients with PIK3CA-mutant disease who progress after first-line therapy with CDK4/ 6 inhibitor plus ET is still unknown.

ByLieve, a phase 2 multicenter, open-label, two-cohort, noncomparative study of alpelisib + fulvestrant or letrozole, including patients who progressed on or after CDKi + AI 
or fulvestrant (metastatic setting) or with $\leq 1$ line of previous chemotherapy (adjuvant or advanced setting) with the primary endpoint of patients alive and without disease progression at 6 months, will be determinant to this question. Although at the first interim analysis, the fulvestrant cohort seems to be better than the letrozolo cohort, the data are still immature [63].

Finally, given the likelihood of the emergence of driver mutations in the PIK3CA gene secondary to previous ET + CDK4/6 inhibitors, combined PI3K or FGFR inhibitors with CDK4/ 6 inhibitors, or with other target agents in triplet combinations, seems to be a promising strategy to overcome resistance to single-agent CDK4/6 inhibitors for the early phase of HR+ HER2 - breast cancer (Table 5).

Despite the remarkable advances in scientific knowledge, the optimal treatment algorithm in $\mathrm{HR}+\mathrm{ABC}$ is still uncertain. However, a strategy based on (1) which agents where used previously, (2) the burden of the disease, (3) the patient's preference, (4) costs and availability seems to be the sensible choice. Obviously, as the HR+ ABC treatment landscape evolves to include CDK4/6 inhibitors + ET as first-line therapy, later-line therapies will need to address those patients who have progressed during or after CDK4/6 inhibitor + ET (Figure 4).

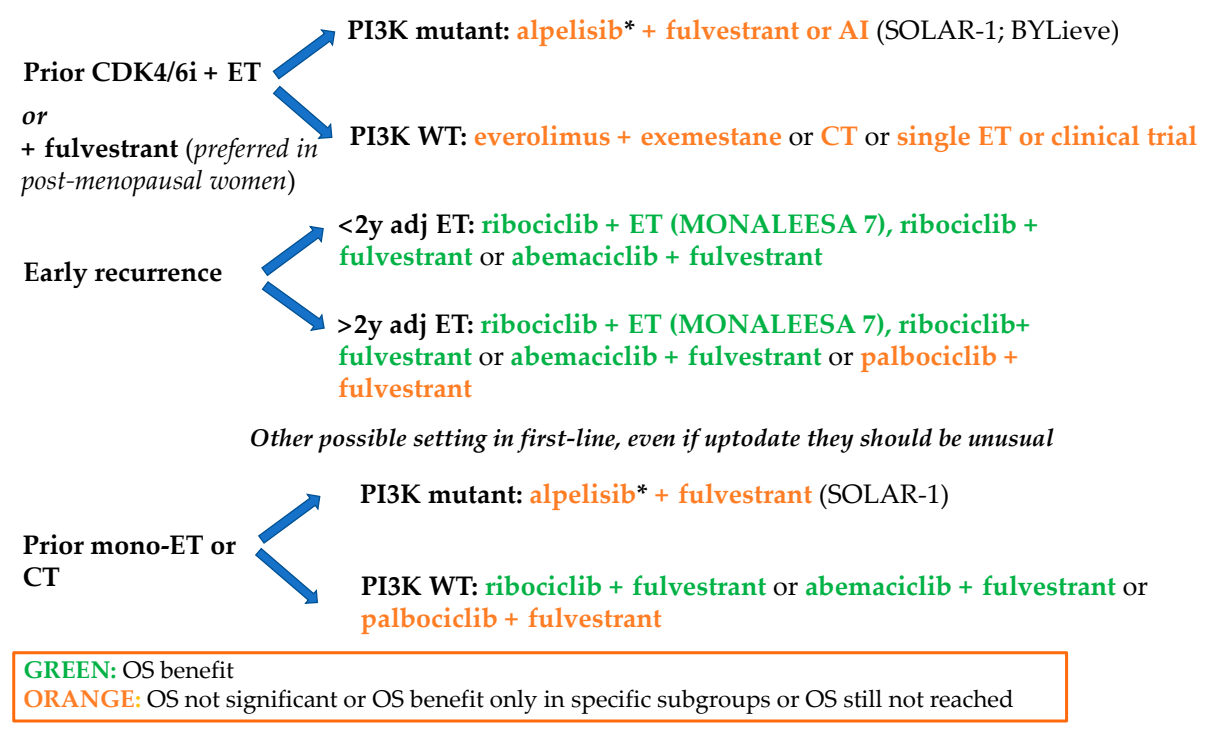

Figure 4. Proposed algorithm of HR+, HER2- advanced breast cancer treatment. Abbreviations: CT, chemotherapy; ET, endocrine therapy with aromatase inhibitor or tamoxifen \pm ovarian suppression; AI, aromatase inhibitor. ${ }^{*}$ Alpelisib is recently approved only after disease progression following endocrine therapy as monotherapy.

Moreover, the potential mechanisms of resistance to CDK4/6i suggested by preclinical genomic and transcriptomic analyses of pathways deserve further clinical investigation (larger patient datasets and prospective studies). Also, analysis of single nucleotide polymorphisms (metabolic biomarkers), the most common type of genetic variation, may add information to predict response to CDK4/6 inhibitors at the patient level [31].

Furthermore, body composition parameters may influence the prognosis in patients receiving CDK4/6 inhibitors. In a retrospective study, baseline sarcopenia (skeletal muscle index $<40$ ) was retrospectively associated with a significantly worse PFS, whereas a high visceral fat index and higher visceral fat density were associated with better PFS [64].

Finally, the analysis of tumor tissue (still the standard) should be integrated with liquid biopsy, and longitudinal ctDNA monitoring can potentially profile the baseline mutational landscape, as well as emerging genomic clonal/subclonal mechanisms of resistance (and possibly actionable) under selective pressure of CDK4/6 inhibitors. 
Table 5. Ongoing studies of multiple combination treatments with CDK4/6 inhibitors.

\begin{tabular}{|c|c|c|c|c|c|}
\hline Trial & Treatment Arms & Phase & Study Population & Primary Endpoint & Status \\
\hline $\begin{array}{l}\text { Study of AZD2014 and palbociclib in patients } \\
\text { with estrogen receptor positive (ER+) metastatic } \\
\text { breast cancer (PASTOR) }\end{array}$ & $\begin{array}{c}\text { Vistusertib (mTOR inhibitor) + } \\
\text { palbociclib + fulvestrant } \\
\text { Placebo + palbociclib + fulvestrant }\end{array}$ & $1 / 2$ & $\begin{array}{c}\text { ER+ locally advanced or MBC in } \\
\text { postmenopausal patients pretreated with } \\
\text { hormonal therapy }\end{array}$ & PFS & $\begin{array}{l}\text { Completed no results } \\
\text { posted }\end{array}$ \\
\hline $\begin{array}{c}\text { Copanlisib, letrozole, and palbociclib in treating } \\
\text { patients with hormone receptor positive HER2 } \\
\text { negative stage I-IV breast cancer }\end{array}$ & $\begin{array}{l}\text { Copanlisib (PI3K inhibitor) + letrozole } \\
\text { Copanlisib + letrozole + palbociclib }\end{array}$ & $1 b / 2$ & $\begin{array}{c}\text { ER+/HER2 - postmenopausal any stage } \\
\text { breast cancer }\end{array}$ & Change in Ki-67, DLT & Recruiting \\
\hline $\begin{array}{l}\text { Ipatasertib plus Palbociclib and fulvestrant } \\
\text { versus placebo plus Palbociclib and fulvestrant } \\
\text { in hormone receptor positive and HER2 } \\
\text { negative locally advanced unresectable or } \\
\text { metastatic breast cancer (IPATunity150) }\end{array}$ & $\begin{array}{l}\text { Ipatasertib }(\text { AKT inhibitor })+ \\
\text { palbociclib }+ \text { fulvestrant versus placebo } \\
+ \text { palbociclib }+ \text { fulvestrant }\end{array}$ & $1 \mathrm{~b} / 3$ randomized & $\begin{array}{l}\text { HR+ HER2 - ABC progressed during } \\
\text { adjuvant ET or the initial } 12 \text { months of } \\
\text { first-line ET }\end{array}$ & PFS & Recruiting \\
\hline $\begin{array}{l}\text { Ribociclib in combination with everolimus } \\
\text { (RAD001) and exemestane in the treatment of } \\
\text { postmenopausal women with hormone receptor } \\
\text { positive, HER2 negative locally advanced or } \\
\text { metastatic breast cancer }\end{array}$ & $\begin{array}{l}\text { Ribociclib, exemestane and everolimus } \\
\text { versus ribociclib and exemestane }\end{array}$ & $\begin{array}{l}\text { Nonrandomized, } \\
\text { two arms, parallel } \\
\text { assignment }\end{array}$ & $\begin{array}{l}\text { Recurrence while on, or within } 12 \text { months } \\
\text { of end of, adjuvant treatment with } \\
\text { letrozole or anastrozole, or progression } \\
\text { while on, or within } 1 \text { month of end of, } \\
\text { letrozole or anastrozole treatment for } \\
\text { ABC }\end{array}$ & DLT and DCR & Completed \\
\hline $\begin{array}{l}\text { LEE011 in combination with fulvestrant and } \\
\text { alpelisib or buparlisib in the treatment of } \\
\text { postmenopausal women with hormone receptor } \\
\text { positive, HER2 negative locally recurrent or } \\
\text { advanced metastatic breast cancer }\end{array}$ & $\begin{array}{l}\text { LEE011 + fulvestrant + alpelisib or } \\
\text { LEE011 + fulvestrant + buparlisib or } \\
\text { LEE011 + fulvestrant }\end{array}$ & $\begin{array}{c}1 \mathrm{~b} / 2 \\
\text { nonrandomized }\end{array}$ & $\begin{array}{l}\text { HR+, HER2 - locally recurrent or } \\
\text { advanced metastatic breast cancer }\end{array}$ & DLT/PFS & Completed \\
\hline $\begin{array}{l}\text { A study to assess the tolerability and clinical } \\
\text { activity of gedatolisib in combination with } \\
\text { palbociclib/letrozole or palbociclib/fulvestrant } \\
\text { in women with metastatic breast cancer }\end{array}$ & $\begin{array}{l}\text { Gedatolisib + palbociclib/letrozole or } \\
\text { gedatolisib + palbociclib/fulvestrant }\end{array}$ & $1 \mathrm{~b}$ nonrandomized & $\begin{array}{l}\text { HR+, HER2- locally recurrent or } \\
\text { advanced metastatic breast cancer }\end{array}$ & DLT ORR & Recruiting \\
\hline $\begin{array}{l}\text { Abemaciclib in combination with therapies for } \\
\text { patients with metastatic breast cancer }\end{array}$ & $\begin{array}{l}\text { Abemaciclib + letrozole or anastrozole } \\
\text { or tamoxifen or exemestane or } \\
\text { everolimus or trastuzumab or } \\
\text { fulvestrant or pertuzumab }\end{array}$ & $1 b$ & Metastatic breast cancer & DLT & Active, not recruiting \\
\hline $\begin{array}{l}\text { PIPA: combination of PI3 kinase inhibitors and } \\
\text { palbociclib with the subsequent addition of } \\
\text { fulvestrant in PIK3CA-mutant breast } \\
\text { cancers (PIPA) }\end{array}$ & $\begin{array}{c}\text { Palbociclib }+ \text { taselisib or pictilisib }(+ \\
\text { fulvestant) }\end{array}$ & $1 b$ & $\begin{array}{l}\text { Malignant solid tumors; ABC: ER+ } \\
\text { progressed on at least one line of previous } \\
\text { ET, or PIK3CA mutant breast cancer } \\
\text { progressed on at least one line of previous } \\
\text { ET or CT, breast cancer refractory to } \\
\text { standard treatment }\end{array}$ & DLT safety & Active, not recruiting \\
\hline
\end{tabular}

Abbreviations: MBC, metastatic breast cancer; PFS, progression-free survival; DLT, dose-limiting toxicity; ET, endocrine therapy; DCR, disease control rate; CT, chemotherapy. 


\section{Conclusions}

CDK4/6 inhibitors radically changed the treatment of HR+/HER2 - metastatic breast cancer, resulting in a benefit in key clinical outcomes with a manageable safety profile. In this review, we reported the mechanism of action of CDK4/6 inhibitors and their implications in current clinical practice. However, intrinsic or acquired resistance can cause disease progression in a large number of patients and the understanding of the mechanism of resistance is an urgent clinical need. We described the potential mechanism of resistance and the forthcoming strategies to enhance CDK $4 / 6$ inhibitors efficacy in improving survival and quality of life of patients. Redefining therapeutic algorithms taking into account the basal genomic profiles and the selective pressure that may occur during therapy will be the best way to personalize cancer care in patients with HR+, HER2 - ABC. Although it could be interesting, whole genomic evaluation is feasible only in experimental clinical trials. But evaluation of single gene mutation, such as PIK3CA, is a close and important evaluation because targetable treatment is available and thus is soon to be introduced into clinical practice. Further research strategies on studies investigating the best sequence or the reported outcomes of triplet therapies, always balancing efficacy and safety, are also awaited.

Funding: This article received no external funding.

Institutional Review Board Statement: Not applicable.

Informed Consent Statement: Not applicable.

Conflicts of Interest: All authors received a speaker honorarium from Novartis. The authors declare that sponsor had no role in the design, execution, interpretation, or writing of the article.

\section{References}

1. Razavi, P.; Chang, M.T.; Xu, G.; Bandlamudi, C.; Ross, D.S.; Vasan, N.; Cai, Y.; Bielski, C.M.; Donoghue, M.T.A.; Jonsson, P.; et al. The Genomic Landscape of Endocrine-Resistant Advanced Breast Cancers. Cancer Cell 2018, 34, 427-438. [CrossRef] [PubMed]

2. Musgrove, E.A.; Sutherland, R.L. Biological determinants of endocrine resistance in breast cancer. Nat. Rev. Cancer 2009, 9, 631-643. [CrossRef] [PubMed]

3. Murphy, C.G.; Dickler, M.N. Endocrine resistance in hormone-responsive breast cancer: Mechanisms and therapeutic strategies. Endocr. Relat. Cancer 2016, 23, 337-352. [CrossRef] [PubMed]

4. Toy, W.; Shen, Y.; Won, H.; Green, B.; Sakr, R.A.; Will, M.; Li, Z.; Gala, K.; Fanning, S.; King, T.A.; et al. ESR1 ligand-binding domain mutations in hormone-resistant breast cancer. Nat. Genet. 2013, 45, 1439-1445. [CrossRef]

5. Hayes, E.L.; Lewis-Wambi, J.S. Mechanisms of endocrine resistance in breast cancer: An overview of the proposed roles of noncoding RNA. Breast Cancer Res. 2015, 17, 40. [CrossRef]

6. Giacinti, L.; Claudio, P.P.; Lopez, M.; Giordano, A. Epigenetic Information and Estrogen Receptor Alpha Expression in Breast Cancer. Oncologist 2006, 11, 1-8. [CrossRef]

7. Fan, A.X.C.; Radpour, R.; Haghighi, M.M.; Kohler, C.; Xia, P.; Hahn, S.; Holzgreve, W.; Zhong, X.Y. Mitochondrial DNA content in paired normal and cancerous breast tissue samples from patients with breast cancer. J. Cancer Res. Clin. Oncol. 2009, 135, 983-989. [CrossRef]

8. Leary, A.F.; Drury, S.; Detre, S.; Pancholi, S.; Lykkesfeldt, A.E.; Martin, L.A.; Dowsett, M.; Johnston, S.R.D. Lapatinib restores hormone sensitivity with differential effects on estrogen receptor signaling in cell models of human epidermal growth factor receptor 2-negative breast cancer with acquired endocrine resistance. Clin. Cancer Res. 2010, 16, 1486-1497. [CrossRef]

9. Miller, T.W.; Hennessy, B.T.; González-Angulo, A.M.; Fox, E.M.; Mills, G.B.; Chen, H.; Higham, C.; García-Echeverría, C.; Shyr, Y.; Arteaga, C.L. Hyperactivation of phosphatidylinositol-3 kinase promotes escape from hormone dependence in estrogen receptor-positive human breast cancer. J. Clin. Investig. 2010, 120, 2406-2413. [CrossRef]

10. Bosch, A.; Li, Z.; Bergamaschi, A.; Ellis, H.; Toska, E.; Prat, A.; Tao, J.J.; Spratt, D.E.; Viola-Villegas, N.T.; Castel, P.; et al. PI3K inhibition results in enhanced estrogen receptor function and dependence in hormone receptor-positive breast cancer. Sci. Transl. Med. 2015, 7, 283ra51. [CrossRef]

11. Fu, X.; Jeselsohn, R.; Pereira, R.; Hollingsworth, E.F.; Creighton, C.J.; Li, F.; Shea, M.; Nardone, A.; De Angelis, C.; Heiser, L.M.; et al. FOXA1 overexpression mediates endocrine resistance by altering the ER transcriptome and IL-8 expression in ER-positive breast cancer. Proc. Natl. Acad. Sci. USA 2016, 113, E6600-E6609. [CrossRef] [PubMed]

12. O'Leary, B.; Finn, R.S.; Turner, N.C. Treating cancer with selective CDK4/6 inhibitors. Nat. Rev. Clin. Oncol. 2016, 13, 417-430. [CrossRef] [PubMed] 
13. Miller, T.W.; Balko, J.M.; Fox, E.M.; Ghazoui, Z.; Dunbier, A.; Anderson, H.; Dowsett, M.; Jiang, A.; Adam Smith, R.; Maira, S.M.; et al. ER $\alpha$-dependent E2F transcription can mediate resistance to estrogen deprivation in human breast cancer. Cancer Discov. 2011, 1, 338-351. [CrossRef] [PubMed]

14. Guerrero-Zotano, A.L.; Stricker, T.P.; Formisano, L.; Hutchinson, K.E.; Stover, D.G.; Lee, K.M.; Schwarz, L.J.; Giltnane, J.M.; Estrada, M.V.; Jansen, V.M.; et al. ERp Breast cancers resistant to prolonged neoadjuvant letrozole exhibit an e2f4 transcriptional program sensitive to cdk4/6 inhibitors. Clin. Cancer Res. 2018, 24, 2517-2529. [CrossRef] [PubMed]

15. Gelbert, L.M.; Cai, S.; Lin, X.; Sanchez-Martinez, C.; Del Prado, M.; Lallena, M.J.; Torres, R.; Ajamie, R.T.; Wishart, G.N.; Flack, R.S.; et al. Preclinical characterization of the CDK4/6 inhibitor LY2835219: In-vivo cell cycle-dependent/independent anti-tumor activities alone/in combination with gemcitabine. Investig. New Drugs 2014, 32, 825-837. [CrossRef] [PubMed]

16. Chen, P.; Lee, N.V.; Hu, W.; Xu, M.; Ferre, R.A.; Lam, H.; Bergqvist, S.; Solowiej, J.; Diehl, W.; He, Y.A.; et al. Spectrum and degree of CDK drug interactions predicts clinical performance. Mol. Cancer Ther. 2016, 15, 2273-2281. [CrossRef]

17. Hortobagyi, G.N.; Stemmer, S.M.; Burris, H.A.; Yap, Y.S.; Sonke, G.S.; Paluch-Shimon, S.; Campone, M.; Petrakova, K.; Blackwell, K.L.; Winer, E.P.; et al. Updated results from MONALEESA-2, a phase III trial of first-line ribociclib plus letrozole versus placebo plus letrozole in hormone receptor-positive, HER2-negative advanced breast cancer. Ann. Oncol. 2018, 29, 1541-1547. [CrossRef]

18. Tripathy, D.; Im, S.A.; Colleoni, M.; Franke, F.; Bardia, A.; Harbeck, N.; Hurvitz, S.A.; Chow, L.; Sohn, J.; Lee, K.S.; et al. Ribociclib plus endocrine therapy for premenopausal women with hormone-receptor-positive, advanced breast cancer (MONALEESA-7): A randomised phase 3 trial. Lancet Oncol. 2018, 19, 904-915. [CrossRef]

19. Slamon, D.J.; Neven, P.; Chia, S.; Fasching, P.A.; De Laurentiis, M.; Im, S.A.; Petrakova, K.; Val Bianchi, G.; Esteva, F.J.; Martín, M.; et al. Phase III randomized study of ribociclib and fulvestrant in hormone receptor-positive, human epidermal growth factor receptor 2-negative advanced breast cancer: MONALEESA-3. J. Clin. Oncol. 2018, 36, 2465-2472. [CrossRef]

20. Goetz, M.P.; Toi, M.; Campone, M.; Trédan, O.; Bourayou, N.; Sohn, J.; Park, I.H.; Paluch-Shimon, S.; Huober, J.; Chen, S.C.; et al. MONARCH 3: Abemaciclib as initial therapy for advanced breast cancer. J. Clin. Oncol. 2017, 35, 3638-3646. [CrossRef]

21. Sledge, G.W.; Toi, M.; Neven, P.; Sohn, J.; Inoue, K.; Pivot, X.; Burdaeva, O.; Okera, M.; Masuda, N.; Kaufman, P.A.; et al. MONARCH 2: Abemaciclib in combination with fulvestrant in women with HR+/HER2-advanced breast cancer who had progressed while receiving endocrine therapy. J. Clin. Oncol. 2017, 35, 2875-2884. [CrossRef] [PubMed]

22. Finn, R.S.; Crown, J.P.; Lang, I.; Boer, K.; Bondarenko, I.M.; Kulyk, S.O.; Ettl, J.; Patel, R.; Pinter, T.; Schmidt, M.; et al. The cyclin-dependent kinase 4/6 inhibitor palbociclib in combination with letrozole versus letrozole alone as first-line treatment of oestrogen receptor-positive, HER2-negative, advanced breast cancer (PALOMA-1/TRIO-18): A randomised phase 2 study. Lancet Oncol. 2015, 16, 25-35. [CrossRef]

23. Turner, N.C.; Ro, J.; André, F.; Loi, S.; Verma, S.; Iwata, H.; Harbeck, N.; Loibl, S.; Bartlett, C.H.; Zhang, K.; et al. Palbociclib in hormone-receptor-positive advanced breast cancer. N. Engl. J. Med. 2015, 373, 209-219. [CrossRef]

24. Turner, N.C.; Slamon, D.J.; Ro, J.; Bondarenko, I.; Im, S.A.; Masuda, N.; Colleoni, M.; DeMichele, A.; Loi, S.; Verma, S.; et al. Overall survival with palbociclib and fulvestrant in advanced breast cancer. N. Engl. J. Med. 2018, 379, 1926-1936. [CrossRef] [PubMed]

25. Cristofanilli, M.; Turner, N.C.; Bondarenko, I.; Ro, J.; Im, S.A.; Masuda, N.; Colleoni, M.; DeMichele, A.; Loi, S.; Verma, S.; et al. Fulvestrant plus palbociclib versus fulvestrant plus placebo for treatment of hormone-receptor-positive, HER2-negative metastatic breast cancer that progressed on previous endocrine therapy (PALOMA-3): Final analysis of the multicentre, double-blind, phas. Lancet Oncol. 2016, 17, 425-439. [CrossRef]

26. Giuliano, M.; Schettini, F.; Rognoni, C.; Milani, M.; Jerusalem, G.; Bachelot, T.; De Laurentiis, M.; Thomas, G.; De Placido, P.; Arpino, G.; et al. Endocrine treatment versus chemotherapy in postmenopausal women with hormone receptor-positive, HER2-negative, metastatic breast cancer: A systematic review and network meta-analysis. Lancet Oncol. 2019, 20, 1360-1369. [CrossRef]

27. Rossi, V.; Berchialla, P.; Giannarelli, D.; Nisticò, C.; Ferretti, G.; Gasparro, S.; Russillo, M.; Catania, G.; Vigna, L.; Mancusi, R.L.; et al. Should All Patients With HR-Positive HER2-Negative Metastatic Breast Cancer Receive CDK 4/6 Inhibitor As First-Line Based Therapy? A Network Meta-Analysis of Data from the PALOMA 2, MONALEESA 2, MONALEESA 7, MONARCH 3 , FALCON, SWOG and FACT Trials. Cancers 2019, 11, 1661. [CrossRef]

28. Im, S.-A.; Lu, Y.-S.; Bardia, A.; Harbeck, N.; Colleoni, M.; Franke, F.; Chow, L.; Sohn, J.; Lee, K.-S.; Campos-Gomez, S.; et al. Overall Survival with Ribociclib plus Endocrine Therapy in Breast Cancer. N. Engl. J. Med. 2019, 381, 307-316. [CrossRef]

29. DeMichele, A.; Cristofanilli, M.; Brufsky, A.; Liu, X.; Mardekian, J.; McRoy, L.; Layman, R.M.; Rugo, H.S.; Finn, R.S. Overall Survival for First-Line Palbociclib Plus Letrozole vs Letrozole Alone for HR+/HER2-Metastatic Breast Cancer Patients in US Real-World Clinical Practice. Available online: Sabcs.posterview.com (accessed on 20 December 2020).

30. Carter, G.C.; Sheffield, K.M.; Gossai, A.; Huang, Y.-J.; Zhu, Y.E.; Bowman, L.; Smith, E.N.; Mathur, R.; Cohen, A.B.; Baxi, S.; et al. Initial real world treatment patterns and outcomes of Abemaciclib for the treatment of HR+, HER2-metastatic breast cancer. Cancer Res. 2020, 80. [CrossRef]

31. Fogli, S.; Del Re, M.; Curigliano, G.; Van Schaik, R.H.; Lancellotti, P.; Danesi, R. Complications of Treatment Drug-drug interactions in breast cancer patients treated with CDK4/6 inhibitors. Cancer Treat. Rev. 2019, 74, 21-28. [CrossRef]

32. Roncato, R.; Angelini, J.; Pani, A.; Cecchin, E.; Sartore-Bianchi, A.; Siena, S.; De Mattia, E.; Scaglione, F.; Toffoli, G. CDK4/6 Inhibitors in Breast Cancer Treatment: Potential Interactions with Drug, Gene, and Pathophysiological Conditions. Int. J. Mol. Sci. 2020, 21, 6350. [CrossRef] [PubMed] 
33. Roberto, M.; Rossi, A.; Panebianco, M.; Pomes, L.M.; Arrivi, G.; Ierinò, D.; Simmaco, M.; Marchetti, P.; Mazzuca, F. Drug-Drug Interactions and Pharmacogenomic Evaluation in Colorectal Cancer Patients: The New Drug-PIN ${ }^{2}$ System Comprehensive Approach. Pharmaceuticals 2021, 14, 67. [CrossRef]

34. Cardoso, F.; Senkus, E.; Costa, A.; Papadopoulos, E.; Aapro, M.; André, F.; Harbeck, N.; Aguilar Lopez, B.; Barrios, C.H.; Bergh, J.; et al. 4th ESO-ESMO international consensus guidelines for advanced breast cancer (ABC 4). Ann. Oncol. 2018, 29, $1634-1657$. [CrossRef] [PubMed]

35. Turner, N.C.; Liu, Y.; Zhu, Z.; Loi, S.; Colleoni, M.; Loibl, S.; DeMichele, A.; Harbeck, N.; André, F.; Bayar, M.A.M.; et al. Cyclin E1 expression and palbociclib efficacy in previously treated hormone receptor-positive metastatic breast cancer. J. Clin. Oncol. 2019, 37, 1169-1178. [CrossRef] [PubMed]

36. Hurvitz, S.A.; Im, S.-A.; Lu, Y.-S.; Colleoni, M.; Franke, F.A.; Bardia, A.; Harbeck, N.; Chow, L.; Sohn, J.; Lee, K.S.; et al. Phase III MONALEESA-7 trial of premenopausal patients with HR+/HER2 - advanced breast cancer (ABC) treated with endocrine therapy \pm ribociclib: Overall survival (OS) results. J. Clin. Oncol. 2019, 37, LBA1008. [CrossRef]

37. Xi, J.; Oza, A.; Thomas, S.; Ademuyiwa, F.; Weilbaecher, K.; Suresh, R.; Bose, R.; Cherian, M.; Hernandez-Aya, L.; Frith, A.; et al. Retrospective analysis of treatment patterns and effectiveness of palbociclib and subsequent regimens in metastatic breast cancer. JNCCN J. Natl. Compr. Cancer Netw. 2019, 17, 141-147. [CrossRef] [PubMed]

38. Cook, M.; Al Rabadi, L.; Mitri, Z.I. Everolimus and exemestane for the treatment of metastatic hormone receptor-positive breast cancer patients previously treated with CDK4/6 inhibitor based therapies. J. Clin. Oncol. 2019, 37, 1058. [CrossRef]

39. Wander, S.A.; Zangardi, M.; Niemierko, A.; Kambadakone, A.; Kim, L.S.; Xi, J.; Pandey, A.K.; Spring, L.; Stein, C.; Juric, D.; et al. A multicenter analysis of abemaciclib after progression on palbociclib in patients (pts) with hormone receptor-positive (HR+)/HER2- metastatic breast cancer (MBC). J. Clin. Oncol. 2019, 37, 1057. [CrossRef]

40. Pandey, K.; An, H.J.; Kim, S.K.; Lee, S.A.; Kim, S.; Lim, S.M.; Kim, G.M.; Sohn, J.; Moon, Y.W. Molecular mechanisms of resistance to CDK4/ 6 inhibitors in breast cancer: A review. Int. J. Cancer 2019, 145, 1179-1188. [CrossRef]

41. Herrera-Abreu, M.T.; Palafox, M.; Asghar, U.; Rivas, M.A.; Cutts, R.J.; Garcia-Murillas, I.; Pearson, A.; Guzman, M.; Rodriguez, O.; Grueso, J.; et al. Early adaptation and acquired resistance to CDK4/6 inhibition in estrogen receptor-positive breast cancer. Cancer Res. 2016, 76, 2301-2313. [CrossRef]

42. Formisano, L.; Stauffer, K.M.; Young, C.D.; Bhola, N.E.; Guerrero-Zotano, A.L.; Jansen, V.M.; Estrada, M.M.; Hutchinson, K.E.; Giltnane, J.M.; Schwarz, L.J.; et al. Association of FGFR1 with ER $\alpha$ maintains ligand-independent ER transcription and mediates resistance to estrogen deprivation in ER+ breast cancer. Clin. Cancer Res. 2017, 23, 6138-6151. [CrossRef] [PubMed]

43. Álvarez-Fernández, M.; Malumbres, M. Mechanisms of Sensitivity and Resistance to CDK4/6 Inhibition. Cancer Cell 2020, 37, 514-529. [CrossRef] [PubMed]

44. Finn, R.S.; Liu, Y.; Zhu, Z.; Martin, M.; Rugo, H.S.; Diéras, V.; Im, S.-A.; Gelmon, K.A.; Harbeck, N.; Lu, D.R.; et al. Biomarker Analyses of Response to Cyclin-Dependent Kinase 4/6 Inhibition and Endocrine Therapy in Women with Treatment-Naïve Metastatic Breast Cancer. Clin. Cancer Res. 2019, 26, 110-121. [CrossRef] [PubMed]

45. Taylor-Harding, B.; Aspuria, P.J.; Agadjanian, H.; Cheon, D.J.; Mizuno, T.; Greenberg, D.; Allen, J.R.; Spurka, L.; Funari, V.; Spiteri, E.; et al. Cyclin E1 and RTK/RAS signaling drive CDK inhibitor resistance via activation of E2F and ETS. Oncotarget 2015, 6, 696-714. [CrossRef] [PubMed]

46. Tolaney, S.M.; Wardley, A.M.; Zambelli, S.; Hilton, J.F.; Troso-Sandoval, T.A.; Ricci, F.; Im, S.A.; Kim, S.B.; Johnston, S.R.; Chan, A.; et al. Abemaciclib plus trastuzumab with or without fulvestrant versus trastuzumab plus standard-of-care chemotherapy in women with hormone receptor-positive, HER2-positive advanced breast cancer (monarcHER): A randomised, open-label, phase 2 trial. Lancet Oncol. 2020, 21, 763-775. [CrossRef]

47. Bardia, A.; Su, F.; Solovieff, N.; Im, S.-A.; Sohn, J.; Lee, K.S.; Campos-Gomez, S.; Jung, K.H.; Vazquez, R.V.; Lu, Y.-S.; et al. Abstract CT141: Genetic landscape of premenopausal HR+/HER2- advanced breast cancer (ABC) based on comprehensive circulating tumor DNA analysis and association with clinical outcomes in the Phase III MONALEESA-7 trial. Cancer Res. Am. Assoc. Cancer Res. 2019, 79, 141.

48. Chia, S.; Su, F.; Neven, P.; Im, S.-A.; Petrakova, K.; Bianchi, G.V.; He, W.; Rodriguez-Lorenc, K.; Taran, T.; Babbar, N.; et al. Abstract PD2-08: Gene expression analysis and association with treatment response in postmenopausal patients with hormone receptor-positive, HER2-negative advanced breast cancer in the MONALEESA-3 study. Cancer Res. Am. Assoc. Cancer Res. 2020, 80,8 .

49. Tolaney, S.; Sahebjam, S.; Le Rhun, E.; Lin, N.; Markel Bear, M.; Yang, Z.; Chen, Y.; Anders, C. Abstract P1-19-01: A phase 2 study of abemaciclib in patients with leptomeningeal metastases secondary to HR+, HER2- breast cancer. Cancer Res. Am. Assoc. Cancer Res. 2019, 79, 19.

50. O'leary, B.; Cutts, R.J.; Liu, Y.; Hrebien, S.; Huang, X.; Fenwick, K.; André, F.; Loibl, S.; Loi, S.; Garcia-Murillas, I.; et al. The Genetic Landscape and Clonal Evolution of Breast Cancer Resistance to Palbociclib plus Fulvestrant in the PALOMA-3 Trial. Cancer Discov. 2018, 8, 1390-1403. [CrossRef]

51. Mao, P.; Cohen, O.; Kowalski, K.J.; Kusiel, J.G.; Buendia-Buendia, J.E.; Cuoco, M.S.; Exman, P.; Wander, S.A.; Waks, A.G.; Nayar, U.; et al. Acquired FGFR and FGF Alterations Confer Resistance to Estrogen Receptor (ER) Targeted Therapy in ER + Metastatic Breast Cancer. Clin. Cancer Res. 2020, 26, 5974-5989. [CrossRef] 
52. Formisano, L.; Lu, Y.; Servetto, A.; Hanker, A.B.; Jansen, V.M.; Bauer, J.A.; Sudhan, D.R.; Guerrero-Zotano, A.L.; Croessmann, S.; Guo, Y.; et al. Aberrant FGFR signaling mediates resistance to CDK4/6 inhibitors in ER+ breast cancer. Nat. Commun. 2019, 10, 1-14. [CrossRef]

53. O’Leary, B.; Cutts, R.; Huang, X.; Hrebien, S.; Liu, Y.; Garcia-Murillas, I.; Andre, F.; Loi, S.; Loibl, S.; Cristofanilli, M.; et al. Genomic markers of early progression on fulvestrant with or without palbociclib for ER+ advanced breast cancer in the PALOMA-3 trial. J. Clin. Oncol. 2019, 37, 1010. [CrossRef]

54. Portman, N.; Milioli, H.H.; Alexandrou, S.; Coulson, R.; Yong, A.; Fernandez, K.J.; Chia, K.M.; Halilovic, E.; Segara, D.; Parker, A.; et al. MDM2 inhibition in combination with endocrine therapy and CDK4/6 inhibition for the treatment of ER-positive breast cancer. Breast Cancer Res. 2020, 22, 1-17. [CrossRef]

55. Vilgelm, A.E.; Saleh, N.; Shattuck-Brandt, R.; Riemenschneider, K.; Slesur, L.; Chen, S.C.; Johnson, C.A.; Yang, J.; Blevins, A.; Yan, C.; et al. MDM2 antagonists overcome intrinsic resistance to CDK4/6 inhibition by inducing p21. Sci. Transl. Med. 2019, 11, eaav7171. [CrossRef] [PubMed]

56. Bonechi, M.; Galardi, F.; Biagioni, C.; De Luca, F.; Bergqvist, M.; Neumüller, M.; Guarducci, C.; Boccalini, G.; Gabellini, S.; Migliaccio, I.; et al. Plasma thymidine kinase-1 activity predicts outcome in patients with hormone receptor positive and HER2 negative metastatic breast cancer treated with endocrine therapy. Oncotarget 2018, 9, 16389-16399. [CrossRef] [PubMed]

57. McCartney, A.; Biagioni, C.; Schiavon, G.; Bergqvist, M.; Mattsson, K.; Migliaccio, I.; Benelli, M.; Romagnoli, D.; Bonechi, M.; Boccalini, G.; et al. Prognostic role of serum thymidine kinase 1 activity in patients with hormone receptor-positive metastatic breast cancer: Analysis of the randomised phase III Evaluation of Faslodex versus Exemestane Clinical Trial (EFECT). Eur. J. Cancer 2019, 114, 55-66. [CrossRef] [PubMed]

58. Li, Z.; Razavi, P.; Li, Q.; Toy, W.; Liu, B.; Ping, C.; Hsieh, W.; Sanchez-Vega, F.; Brown, D.N.; Da Cruz Paula, A.F.; et al. Loss of the FAT1 Tumor Suppressor Promotes Resistance to CDK4/6 Inhibitors via the Hippo Pathway. Cancer Cell 2018, 34, 893-905.e8. [CrossRef] [PubMed]

59. Vijayaraghavan, S.; Karakas, C.; Doostan, I.; Chen, X.; Bui, T.; Yi, M.; Raghavendra, A.S.; Zhao, Y.; Bashour, S.I.; Ibrahim, N.K.; et al. CDK4/6 and autophagy inhibitors synergistically induce senescence in $\mathrm{Rb}$ positive cytoplasmic cyclin e negative cancers. Nat. Commun. 2017, 8, 15916. [CrossRef]

60. Buono, G.; Gerratana, L.; Bulfoni, M.; Provinciali, N.; Basile, D.; Giuliano, M.; Corvaja, C.; Arpino, G.; Del Mastro, L.; De Placido, S.; et al. Circulating tumor DNA analysis in breast cancer: Is it ready for prime-time? Cancer Treat. Rev. 2019, 73, 73-83. [CrossRef]

61. McCartney, A.; Migliaccio, I.; Bonechi, M.; Biagioni, C.; Romagnoli, D.; De Luca, F.; Galardi, F.; Risi, E.; De Santo, I.; Benelli, M.; et al. Mechanisms of Resistance to CDK4/6 Inhibitors: Potential Implications and Biomarkers for Clinical Practice. Front. Oncol. 2019, 9, 666. [CrossRef]

62. André, F.; Ciruelos, E.; Rubovszky, G.; Campone, M.; Loibl, S.; Rugo, H.S.; Iwata, H.; Conte, P.; Mayer, I.A.; Kaufman, B.; et al. Alpelisib for PIK3CA -Mutated, Hormone Receptor-Positive Advanced Breast Cancer. N. Engl. J. Med. 2019, 380, $1929-1940$. [CrossRef] [PubMed]

63. Rugo, H.S.; Ruiz Borrego, M.; Chia, S.K.L.; Juric, D.; Turner, N.C.; Drullinsky, P.; Lerebours, F.; Bianchi, G.V.; Nienstedt, C.C.; Ridolfi, A.; et al. Alpelisib (ALP) + endocrine therapy (ET) in patients (pts) with PIK3CA-mutated hormone receptor-positive $(\mathrm{HR}+)$, human epidermal growth factor-2-negative (HER2-) advanced breast cancer (ABC): First interim BYLieve study results. J. Clin. Oncol. 2019, 37, 1040. [CrossRef]

64. Franzoi, M.A.; Eiger, D.; Ameye, L.; Ponde, N.; Caparica, R.; De Angelis, C.; Brandão, M.; Desmedt, C.; Di Cosimo, S.; Kotecki, N.; et al. Clinical Implications of Body Mass Index in Metastatic Breast Cancer Patients Treated With Abemaciclib and Endocrine Therapy. J. Natl. Cancer Inst. 2020, 116. [CrossRef] 